\title{
Feeling like a State. The Sentiments Tide of Swiss Diplomacy through the Eye of the Algorithm
}

\author{
ANDRÉ OUREDNIK, GUIDO KOLLER, PETER FLEER, STEFAN NELLEN
}

\section{Introduction}

Sentiments and emotions are transdisciplinary concepts. Depending on research focus, their expression in words and actions is triggered by a somatic event, emerges from the depths of the individual psyche or crystallises in a given sociolinguistic environment. Prior to all analysis in this paper, we reject the idea of any single origin of emotions; our basic posture is to consider them at the interface of a plurality of origins and scales of reality, ranging from the individual to the global context, from the immediate event to the long timescale of biological evolution. By analysing a set of historical documents produced by the Swiss administration in the first half of the $20^{\text {th }}$ century, we ask whether emotions can be observed throughout the years at the regional scale of continents and countries. ${ }^{1}$ We ask whether variation in their expression and intensity correlates with historical events ${ }^{2}$ and the evolution of diplomatic and administrative practices. The novelty of this line of questioning lies in spanning several fields of research and implies both methodological and theoretical reflexivity to contain its historical object.

Our work requires adopting a sremote reading, posture. We shall use ssentiment analysis`, a wellknown set of computer-assisted methods for identifying subjective affects in data; in our case, texts written in a natural language. We shall combine the individual texts of our corpus based on place and time of composition and measure the sentiments expressed in these aggregates. Because the very idea of a super-individual emotion can only be constructed in this assembling, quantitative manner, we dedicate an important part of this paper to explicate the extent of the concept of sentiment in this methodological context and to reflect upon its contribution to our general understanding of sentiments of social groups and institutions.

The nature of our documents also induces another methodological challenge. Traditionally, textual sentiment analysis (TSA) is used to observe the evolution of a book's mood throughout individual chapters, detect the fingerprint of an author, detect passages for close reading, sort mail or follow the trends on the Web 2.0 with regard to a specific topic. Curricular examples of TSA often rely on public domain fiction. Its commercial applications focus on customer feedback over e-mails, blogs and social media. In all of these examples, strongly expressive language is frequent, including accounts of state officials. Sentiment is most straightforward when reading of »crooked Hillary Clinton [...] the worst looser 
of all times $\aleph^{3}$ or "Fiona and her team at the Tudor Club - delicious lunch! Important social club«. ${ }^{4}$ Twitter, of course, provides real time access to massive textual data and has received understandable focus in digital politology. ${ }^{5}$ But how does TSA deal with diplomatic language from the first half of the $20^{\text {th }}$ century?

\section{What Are Political Reports}

Doubtlessly, the difficulty in assessing subjective affects in diplomatic documents will rise with their degree of formality. In this case study, we concentrate on the corpus of the political reports of Swiss ambassadors.

\section{Language specificities}

Since the second half of the $19^{\text {th }}$ century, Swiss embassies in an increasing number of world cities have to send regular reports (usually on a monthly basis) on the political and military situation in their host countries to the Federal Department of Foreign Affairs (FDFA) in Bern. These reports served to inform the government about the international situation and thus were the basis for making foreign and security policy decisions. These so-called >political and military reports ${ }^{6}$ are valuable sources for historic analysis under different approaches. In particular, they contain information about the official Swiss perception of foreign nations and their political developments. As internal diplomatic documents, they are written by diplomats in diplomatic wording, but they do not reflect the polished diplomatic style of official utterances. The style is the result of the combination of a diplomatic culture that developed in the inter-war period and professionalised after the World War II, and many years of individual training in the course of a diplomatic career. As such, these documents are both institutional and subjective and can be questioned for sentiments or value judgements. One recent example is the confidential report by the Swiss ambassador in Washington during the diplomatic crisis of the mid-1990s, caused by the critique against the Swiss policy during World War II. The report was leaked and published, and the Swiss ambassador had to resign. ${ }^{7} \mathrm{He}$

\section{Diplomats and the evolving culture of diplomacy}

The authors of our corpus, the diplomats, are experts. ${ }^{8}$ They have their own professional habitus and language (cf. infra). We could speak of a culture of diplomacy that ritualises feelings and guides the risk associated with them in orderly ways. The term sdiplomacy, has a twofold meaning: On the one hand, it signifies the substance of diplomatic affairs and on the other, the style and manner in which such businesses are conducted. Traditionally, at the centre of diplomatic activity used to be the representation. While explaining the formation of diplomatic forms and styles in Europe, Pietro Gerbore speaks of a diplomatic ceremonial of envoys: In Venice and Rome, for example, the diplomats accompanied the dignitaries because they represented the prince or the government of their country. ${ }^{9}$ Rank, priority and precedence play(ed) an important role in the diplomatic game. ${ }^{10}$ Today, state visits still display old elements of such ceremonies: the red carpet, the music band, the (military) honour guard, the festive reception, etc. ${ }^{11}$

In the second half of the $20^{\text {th }}$ century, the design of diplomacy was less solemn. Negotiations, correspondence (notes, reporting), protection of interests, press and propaganda were typical tasks of an embassy. ${ }^{12}$ These activities had been regulated internationally in the Vienna Convention of 1961. The regulation was necessary because, with the growth of the number of states and the expansion of state functions, the number of embassies and diplomats had grown rapidly. ${ }^{13}$

Switzerland initially had more consulates than diplomatic missions. On the eve of World War II, the confederation maintained a network of 121 consular offices, some of them professional and some honorary. ${ }^{14}$ The reasons for the extension of the diplomatic service were above all the increasing Swiss exports and emigration. ${ }^{15}$ Compared to the professionalisation of the Foreign Service in Germany and France, Switzerland had a considerable backlog. For a long time, it used private contractors for bilateral negotiations, such as entrepreneurs who represented Swiss interests in the country where they had their business. In Asia, the Federal Council (the Swiss government) appointed the 


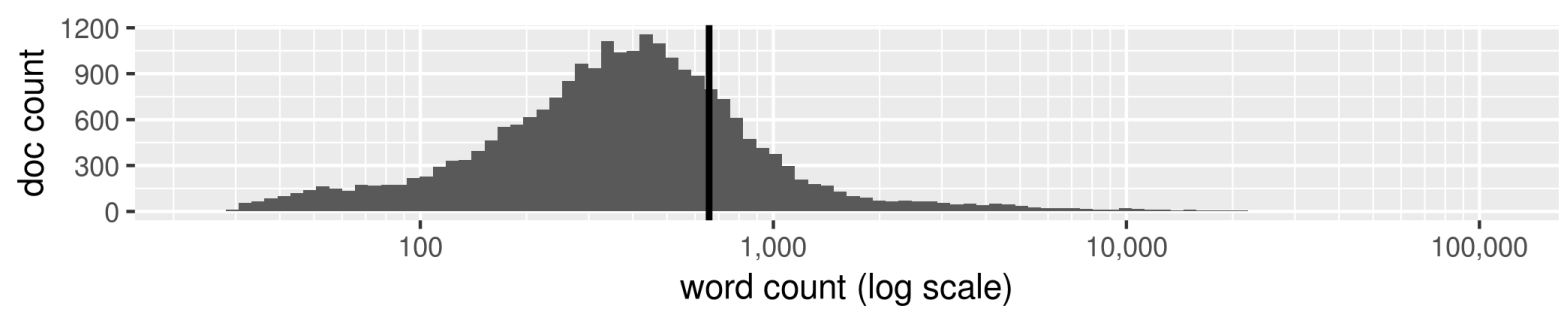

Figure 1: Count of reports in function of their number of words. ${ }^{27}$ The average ( 660 words, black line) lies far beyond the median (380 words, maximum peak of count), due to a few documents exceeding 10 pages (10,000 words).

first permanent head of mission for Asia only in 1906, at the Government of Japan. ${ }^{16}$ The decolonisation after World War II brought a considerable growth. Later, the title Ambassador supplanted that of the envoy (French: ıministre `). The head of mission in Paris was the first to receive the title of Ambassador in 1957. ${ }^{17}$

Today, the FDFA recruits diplomats in a multistage admission competition, the so-called Concours, and trains them for around two years at home and abroad. For its Concours diplomatique 2018, the FDFA was seeking "young and innovative talents who use their potential of diplomacy to actively shape Swiss foreign policy «. ${ }^{18}$ Their activities »in the context of international relations, including in the fields of politics, economics, international law, environment and culture contain notably ${ }^{19}$ attending a country, attending conferences and organisations, answering legal questions in the context of international relations, representing the interests of Switzerland (economy, technology, politics, culture), supporting Swiss companies and establishing and maintaining networks.

Keller discussed the "democratization of the diplomatic corps " in the context of the Concours. ${ }^{20}$ Portraying Swiss diplomats in Paris, Washington, London, Moscow, New York and Cologne, he came to the conclusion that "the person shaped the activity «, ${ }^{21}$ meaning that it is not the development in the diplomatic service that shapes the activities of an ambassador but the experiences he has made in his previous career. He argued that the most important instrument to influence the activity of a diplomatic post is reduced to the selection of its chargé d'affaires. ${ }^{22}$ TSA could verify such statements against a broad empirical foundation, for instance by following the evolution of the language of a given ambassador or by examining correlations between professional promotions or transfer of diplomats in function with statistically measurable linguistic features of his or her reports.

\section{Scope and limitations}

Our algorithmic analysis of the Swiss political reports is of course subject to a series of material contingencies. The original documents of the E2300* fond are printed on paper of diverse qualities and formats, which required scanning and optical character recognition. Furthermore, the political and diplomatic reports are written in many languages, among which 46\% are written in French, ${ }^{23}$ an official language as well in Switzerland as in the international diplomatic circles since the $18^{\text {th }}$ century. Coming after in terms of frequency are German (35\%), English (9\%) and Italian (2\%), and then a series of other languages. Because of the methodological difficulties associated with conducting TSA across multiple languages, we have chosen to focus on the most frequently one, French, at this stage, and constructed our analytical system around it. From our original set of 80,322 documents, we have only kept 23,700 based on the following criteria:

- identified as written in French by their metadata ${ }^{24}$

- >400 characters long (a short paragraph)

- $>20$ single words long after tokenisation ${ }^{25}$

- $\quad>70 \%$ of words clearly identifiable as French ${ }^{26}$

The corpus totals $15,584,725$ words, of which $35 \%$ are associable with an emotion by the FEEL dictionary (cf. infra). Individual reports contain between 24 and 102,000 words. Only 130 documents exceed 10 pages length (Figure 1).

Figures 2 and 3 show that these reports come from all of world's and Europe's regions, respectively. This is 


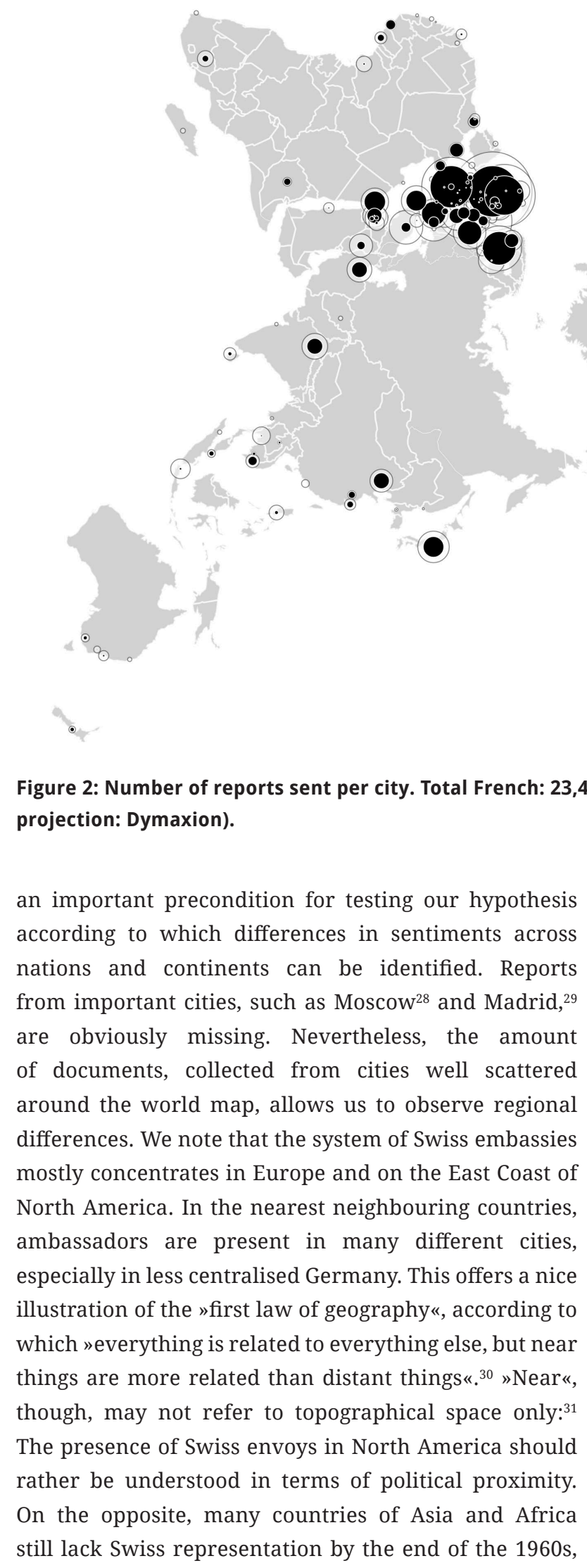

above all countries that only gain independence from colonial powers later on. Geopolitical interest, here, is an obvious factor of explanation. Japan, for instance, who enjoys the status of a colonial power in the Pacific from the second half of the $19^{\text {th }}$ century, also enjoys the presence of a Swiss diplomatic envoy since 1906.

We further hypothesise that sentiments show a chronological evolution, which can be correlated with general or specific political, economic or cultural trends. In such a way, TSA can contribute to a history of the administration, to a description and analysis of diplomatic and administrative practices. For this, we need our data to be sufficiently fine-grained on the historical time scale.

The date of most political reports in our possession is expressed in time spans covering several years. In effect, the dating is not based on the documents themselves but on the associated metadata in the archival database of the Swiss Federal Archives (SFA). Figure 4 illustrates the historical distribution of these dates (cf. Figure 2). 


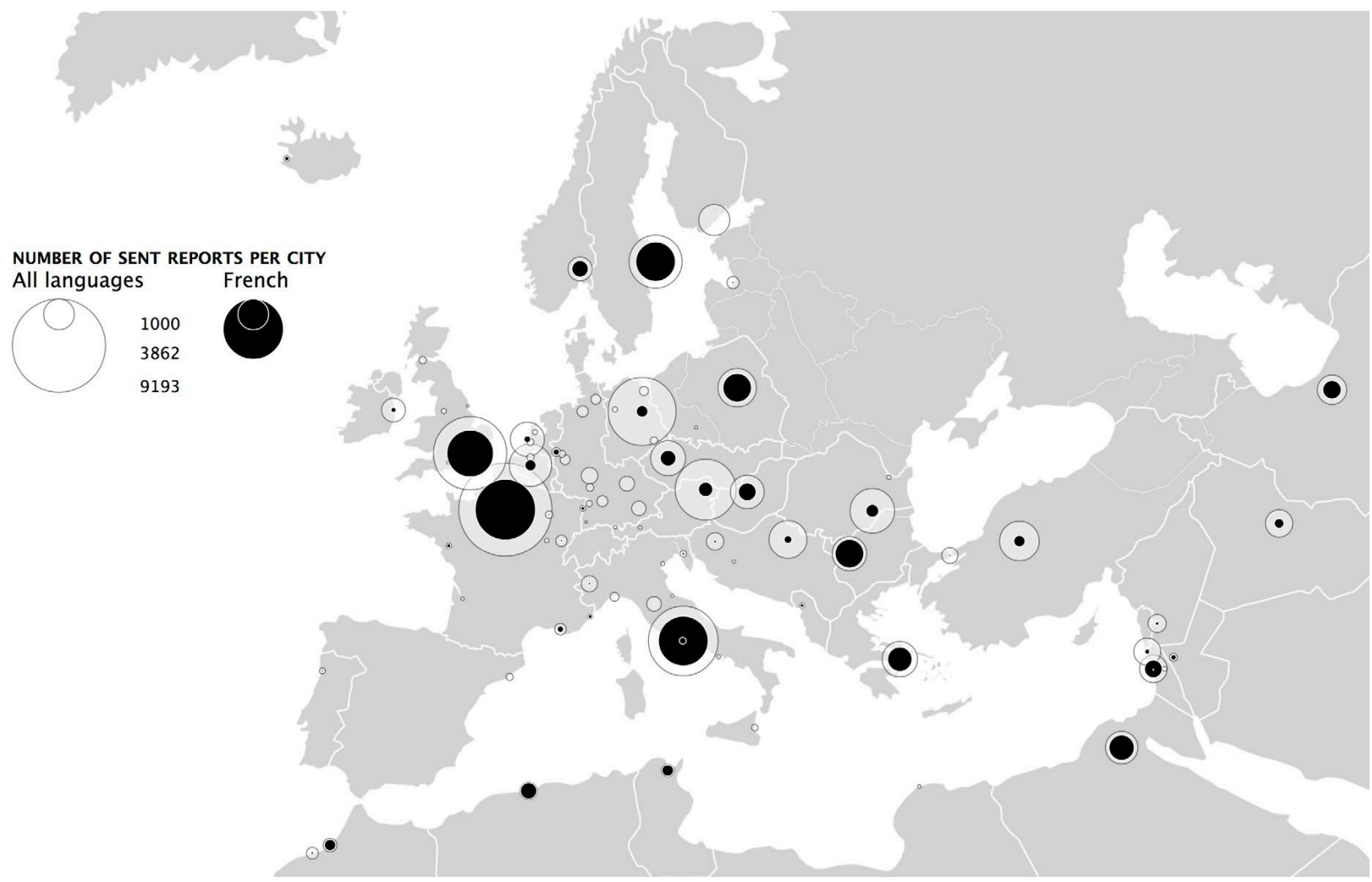

Figure 3: Detail of Figure 2: Europe. (Map projection: Peirce Quincuncial).

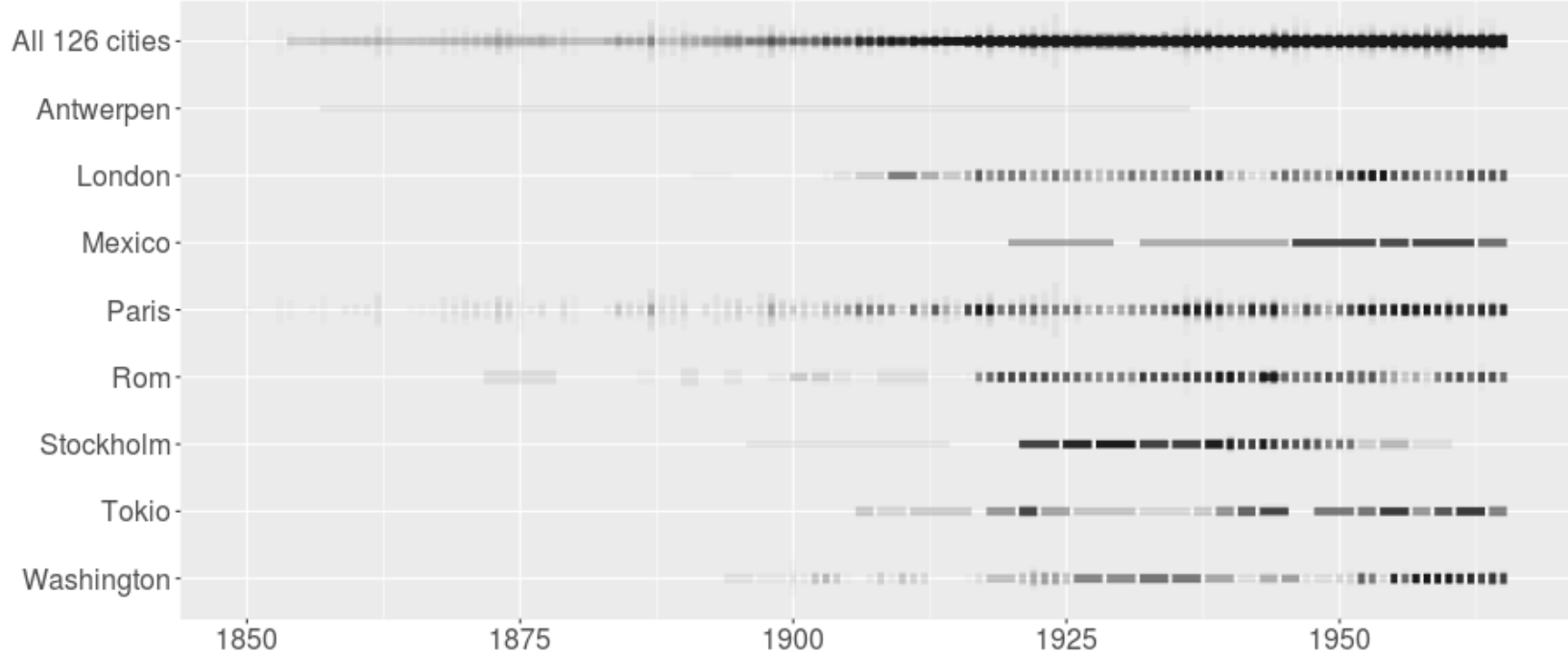

Figure 4: Distribution of documents from selected cities, per city and time span of origin. Line colour is transparent: Light grey lines indicate one or two documents and dark lines multiple documents overlapping in the same time span. The line width is proportional to the number of tokens per document, divided by the line's length. 
As Figure 4 shows, the most densely covered period across all cities, on which we therefore focus, lies between 1920 and 1960. Reports from cities such as Antwerp are few and dated to a single, wide time span (1857-1936) excluding analysis of a historical evolution. Documents from Mexico are more numerous and stem from five different time spans, but the dating precision is still insufficient. On the contrary, cities such as Paris, Washington, Tokyo, London and Stockholm provide a continuous sequence of precisely dated texts. We have selected such cities due to this availability of fine-grained chronological data. We have set the precision threshold to 3 years, meaning that we excluded reports dated from a larger time span from further analysis. This brings us down to 12,364 analysed reports. The next question is whether the language of these texts allows detection of statistically meaningful sentiments.

\section{A State of Practice in Sentiment Analysis}

\section{Sentiments, feelings, affects and emotions}

The European Parliament recently tested TSA of foreign documents to detect translation bias. In case of quantifiable change in mood and sentiment across translations in documents, Whelchel and Fellbaum speak of "misconstrued communications", which the administration seeks to overcome. ${ }^{32}$ Algorithms become its tool of international sentiment expression alignment. Whatever the purpose and chosen method of TSA, making its epistemic posture explicit is essential for its use and the interpretation of its results.

If an algorithm is to attribute sentiments to data of any type, it needs a predefined discrete and finite set of sentiment categories. Whether such a set can be constructed at all is of course in dispute, ${ }^{33}$ as much as the >real differencer between sentiments, feelings, affects, emotions and opinions. ${ }^{34}$ Plamper, like other authors, overcomes the latter by encompassing all of these terms in a meta-concept. ${ }^{35}$ For ourselves, except for >opinion`, we shall treat these terms as synonyms, since their distinction provides no added value in our context. We a better dialogue between neuroscience and the social sciences, i.e. for overcoming rigid postures that oppose, at best, scientist universalism to ideological culturalism and, at worse, phrenology to creationism. Thus, while considering any finite set of sbasic emotions، as an epistemic construct, we also recognise its pragmatic value and necessity.

We retain that natural language provides names for sentiments, which can serve as a classification basis. We also pose that language participates in the mental state of its speaker, by encouraging her to conceive her emotions in a specific way. In turn, her use of a given vocabulary to express her emotions contributes to the reification of this vocabulary and of the associated mental states of other individuals, and thus affects her social environment. Emotions "arise at junctures of social plans «. ${ }^{37}$ This also means that we can expect emotions expressed by individuals in an administrative apparatus to reflect political or historical events, as much as the other way around: Such events are indeed the ultimate expression of the emotions of political bodies. Their analysis can contribute to a history of the administration that is not only the history of the rationality of an institutional order, as Max Weber stressed, ${ }^{38}$ but also the history of ritualising feelings and guiding the risk associated with them, especially in diplomacy.

\section{Polarities and basic emotions}

TSA inherits its basic emotions from research in psychology and neuroscience, for example: ${ }^{39}$

- Ekman, Friesen, Ellsworth: ${ }^{40}$ anger, disgust, fear, joy, sadness, surprise

- Plutchik: ${ }^{41}$ trust, anger, anticipation, disgust, joy, fear, sadness, surprise

- Jack, Garrod, Schyns: ${ }^{42}$ happiness, sadness, fear | surprise, anger | disgust

Most authors working with basic emotions consider these as categories subsuming a wider range. Cheerfulness, zest, contentment, pride, optimism, enthrallment and relief, for example, are all considered as variants of joy by Shaver et al. ${ }^{43}$ Some propose a graduation of basic emotions and derived sentiments, such as remorse as a combination of disgust and sadness (Figure 5). Most include at least four 


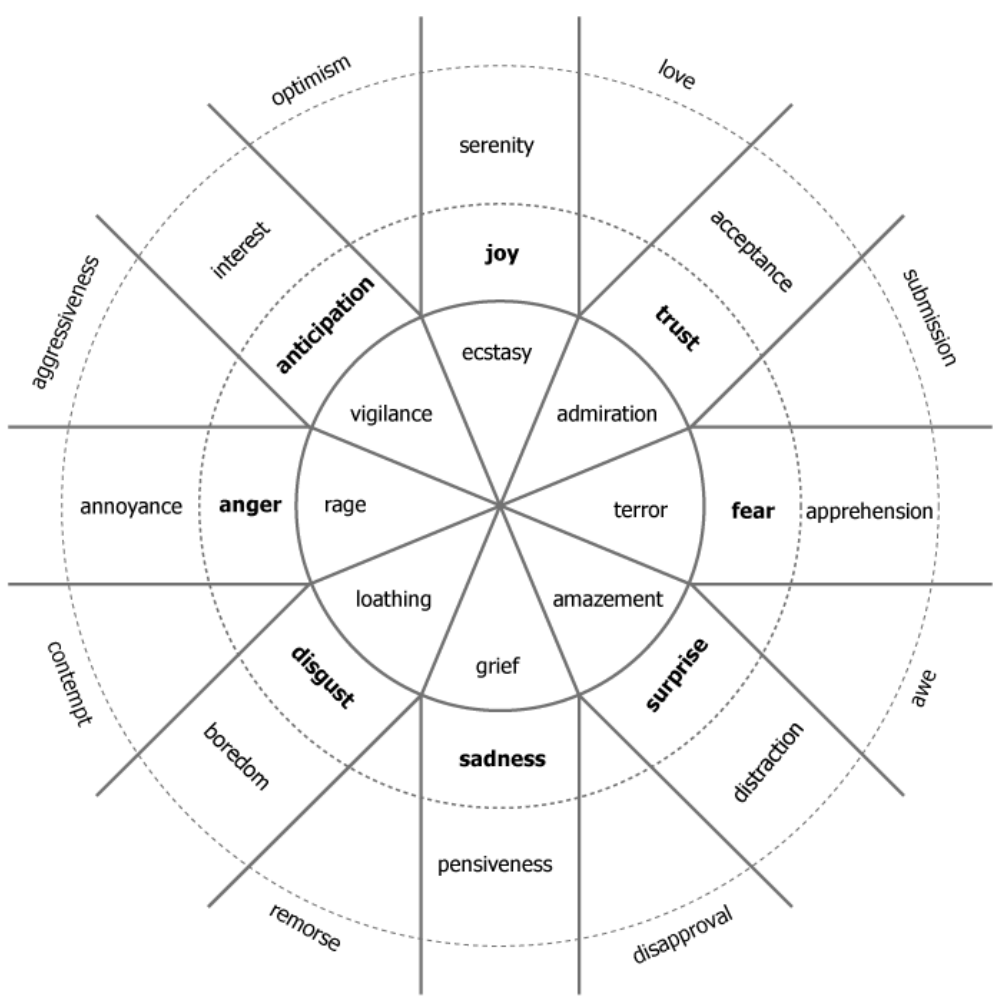

Figure 5: Plutchik's swheel of emotions،. The intensity of emotions weakens with distance from the centre. Similar emotions are placed next to each other and contrasting emotions opposite to each other. Complex emotions appear as combinations of the basic emotions, between the petals of main axes.

emotions among the 'basic ones: anger/rage, happiness/ joy/elation, sadness and fear/anxiety.

Some authors treat basic emotions as distinct from sentiment polarities: positive vs. negative, ${ }^{44}$ also referred to as semantic orientation or valence. ${ }^{45}$ We propose to consider such polarities as highest metasets of basic emotions. For TSA, it is noteworthy that discrete polarities $(-1,1)$ closely relate to the linguistic concept of synonyms and antonyms. Some authors include a neutral valence $(-1,0,1)$ or attribute polarities on a continuous scale of real numbers between -1 and $1{ }^{46}$ translating, for instance, the difference in degree between serenity, joy and ecstasy.

\section{Textual sentiment analysis in popular approaches}

TSA uses mainly two classes of methods to detect sentiments in texts, based on either a lexicon or machine

\section{Lexicon-based approaches}

A lexicon-based approach considers a text as a list of words. It does not analyse its sequential linguistic structure but only frequencies of isolated words (unigrams), predefined phrases or word sequences of uniform length $n$ (n-grams). By constructing the so-called document-term matrix, one seeks to identify individual texts in which some words occur more than in others in the same corpus. Words are lemmatised beforehand to avoid redundant counts of flections (plurals, verb tenses, cases). TSA then treats lemmas as markers of specific sentiments, according to a predefined lexicon.

The most cited lexicon of this kind is the NRCEmoLex,${ }^{47}$ marking 9383 unigrams and 787 bigrams with the positive/negative polarity and with eight Pluchik's emotions. Its authors argue that Pluchik's set, unlike Ekman's, is not composed of mostly negative emotions and is a superset of Ekman's, itself a superset of Jack's.

The use of a lexicon consisting mainly of unigrams to detect sentiments might be surprising. Among its 
numerous limitations is the semantic shift $t^{48}$ of word meanings that necessarily occurs over a time span of over 40 years. In their machine learning-based examination of the of such shifts, Hamilton, Leskovec and Jurafsky showed, for instance, how the English term sawful travels from its 1850s semantic neighbourhood of ssolemn ‘ and 'majestic to its 1900s neighbourhood of sappalling and sterrible.$^{49}$ Other problems of unigram lexicon-based TSA include negation handling: on 13 February 1922, for instance, the Swiss ambassador in Stockholm wrote that the Scandinavians "suffer from the economic crisis as much as us, and we cannot pretend that we are particularly happy (les Scandinaves souffrent de la crise économique comme nous et on ne peut pas prétendre que nous soyons particulièrement heureux) «;0 the word 'heureux ' does appear but means its opposite. Another common example is irrealitis: According to the Swiss ambassador in Washington on 17 November 1958, Mr Walter Robertson, Assistant Secretary of Far Eastern Affairs "would much rejoice in getting rid of New Guinea by ceasing it to the Indonesians, if he governed it (s'il régnait sur la Nouvelle Guinée, il serait trop heureux de s'en débarrasser en la cédant aux Indonésiens)«. ${ }^{51} \mathrm{Mr}$ Robertson might have rejoiced in doing so, but he does not govern Indonesia. Further common problems of unigram-based sentiment analysis are listed by Denis, Cruz-Lara and Bellalem. ${ }^{52}$

Diplomatic language, rich in such wordings, poses a challenge for TSA. Proceeding by word collocation sampling, we found our most emotional lemmas, like 'heureux`, to be mostly used in an unmodified way in our over 5 million emotionally marked lemmas of our corpus. But we did not find, yet, a systematic method for identifying the proportion of such problematic cases such as negation and irrealitis. Word sense disambiguation techniques by machine learning should offer a solution.

\section{Machine learning}

Machine learning approaches consist of straining a sentiment-detection algorithm. The method's advantage lies in its independence from a general-use, contextunspecific lexicon. It relies instead on the dataset itself, from which a straining set of texts is extracted and annotated by human analysts. The construction of a training set is accordingly resource demanding. Authors often reach out to pre-tagged databases of texts, such as user reviews that are both textual and ordinal. The Internet Movie Database, for instance, provides user comments associated with an ordinal rating, ranging from one to ten. ${ }^{53}$ The training itself is based on n-gram frequencies in the training set and can thus be compared to the use of a hidden lexicon. Nevertheless, this hidden lexicon is always, per definition, adapted to the set of texts on which the sentiment detection was trained.

The most used supervised machine learning methods ${ }^{54}$ in sentiment analysis are Naive Bayes Classification; ${ }^{55}$ K-Nearest Neighbours; Support Vector Machines, known for performance in word sense disambiguation; Maximum Entropy Classifiers; Random Forest and Multi-Layer Perceptron. In a recent work, Zhang, Zou and Gan used Convolutional Neural Networks combined with Crossmodality Consistent Regression to integrate predefined lexica in the machine learning process. All of these methods are algorithmically elaborate and mostly need an extensive human-annotated training set. This explains why current research in this field remains essentially methodological. Zhang, Zou and Gan, for instance, only apply their method to standard datasets designed for testing sentiment prediction performance ${ }^{56}$ and conclude that "lexicon embeddings, attention mechanism and CCR are effective in general sentiment analysis.$^{57} \mathrm{~A}$ gap between machine learning and historical research still needs to be bridged. In further work, we endeavour to use this type of methods to construct corpus-oriented sentiment lexica, notably by the use of machine learningsupported word sense induction. ${ }^{58}$

In this study, we focus on a lexicon-based approach with a predefined lexicon. However, we have felt a need to adjust it.

\section{Adjusting to the Context}

\section{A French sentiment lexicon}

We developed our analysis algorithms using the $\mathrm{R}$ programming language. With regard to algorithmic efficiency, we have used the Quanteda package for $\mathrm{R},{ }^{59}$ which includes fast methods for the use of custom 
dictionaries. The aforementioned NRC-EmoLex is directly available in some $\mathrm{R}$ packages, ${ }^{60}$ but it only classifies English lemmas. Our corpus being in French, we base our analysis on the FEEL lexicon ${ }^{61}$ that includes 14,000 French lemmas and bigrams tagged by polarities and a set of six Ekman emotions: anger, disgust, fear, joy, sadness and surprise. The FEEL lexicon results from a human-validated automatic translation and expansion to synonyms of the NRCEmoLex. ${ }^{62}$ FEEL is, to our knowledge, the most complete general-purpose French sentiment lexicon available at the present date.

In order to use it, we have lemmatised our original corpus at the tokens' level using the LEFFF lexicon ${ }^{63}$ of $\sim 550,000$ French words. We have removed French stopwords. ${ }^{64}$ In ulterior work, TreeTagger, ${ }^{65}$ SpaCy ${ }^{66}$ or $U D P i p e^{67}$ shall be used for higher quality lemmatisation.

Authors, political entities, and sentiment dictionary compilers: the three subjects of sentiment expression

Context adjustment is a difficult task of TSA, especially in lexicon-based approaches. Some authors propose specific lexica for domains like finance. ${ }^{68}$ Others develop automatised methods for lexicon-adjustment. ${ }^{69}$ For our purpose, we have manually adjusted the FEEL lexicon, following a preliminary analysis in which we used its original version. We were surprised, in effect, by the most frequent terms in our corpus marked with positive vs. negative polarity in FEEL (Figure 6).

Unsurprisingly, words associated with the exercise of political power occur most frequently in our corpus. Surprisingly, FEEL associates such words with sentiment polarity (Figure 6). To make sense of the lexicon and to define a more solid base for its adjustment, we have decided to distinguish between three types of emotions or, more precisely, between what we shall name the three subject levels of emotional expression. The first two levels reflect what sentiment analysis also defines as subjectivity classification. ${ }^{70}$ The third one, we introduce.

1. Expressions reflecting the feelings of the author(s) of a report. These include striste` or 'heureusement،, formulations such as sde plus en plus (denoting a fear of excess) or negative turns (`non`, `ne pas`).

2. Expressions reflecting emotionally shaped states of political entities, such as 'guerre`, ‘crise` or spaix‘. At the level of the author, these lemmas are objective facts, but they definitely indicate a non-neutral

$\begin{array}{ll}\text { rank lemma } & \text { frequency } \\ 1 \text { pouvoir } & 120136 \\ 2 \text { gouvernement } & 82146 \\ 3 \text { pays } & 71717 \\ 4 \text { potitique } & 70722 \\ 5 \text { état } & 51399 \\ 6 \text { ministre } & 49981 \\ 7 \text { générat } & 46573 \\ 8 \text { grand } & 42568 \\ 9 \text { président } & 42563 \\ 10 \text { devoir } & 42539 \\ 11 \text { contre } & 41728 \\ 12 \text { bien } & 39114 \\ 13 \text { dernier } & 38322 \\ 14 \text { monsieur } & 37140 \\ 15 \text { voutoir } & 34420 \\ 16 \text { guerre } & 32865 \\ 17 \text { donner } & 31156 \\ 18 \text { jour } & 31087 \\ 19 \text { premier } & 30291 \\ 20 \text { sout } & 29896 \\ 21 \text { situationt } & 29196 \\ 22 \text { mettre } & 28808 \\ 23 \text { troutrer } & 28551 \\ 24 \text { part } & 27794 \\ 25 \text { altemanct } & 27019 \\ 26 \text { droit } & 26471 \\ 27 \text { rapport } & 26430 \\ 28 \text { moins } & 25810 \\ 29 \text { aucun } & 25146 \\ 30 \text { peuple } & 24785\end{array}$

Figure 6: The $\mathbf{3 0}$ most frequent polarised lemmas in the corpus, according to the original FEEL lexicon. Turquoise terms marked as positive, and red terms marked as negative. Crossed out terms reflect judgement arbitral of the lexicon authors rather than actual sentiments and were removed prior to further analysis. The full list of removed terms is in the Annex.

disposition on a higher social level. In the context of international diplomacy, military action usually denotes negative mutual disposition. We shall come back to the notion of super-individual emotions in the >Global Results and Interpretation ‘ section.

3. Expressions reflecting judgement arbitral or deliberate values of the lexicon's authors. Such include the association of scommunism s with fear, anger and a negative polarity; 'gauche >conservateur « were marked as negative; s socialisme was marked as positive but was also associated with fear and disgust by FEEL; ssocialister was marked as positive but was associated with sadness and anger. ‘Droite`, 'nation`, >troupe`, ‘militaire`, sarmer`, ssoldat positive; 'gouvernement ' was marked as positive but associated with fear. For incomprehensible reasons, some country names such as sAllemage were marked positive while most others were not. 


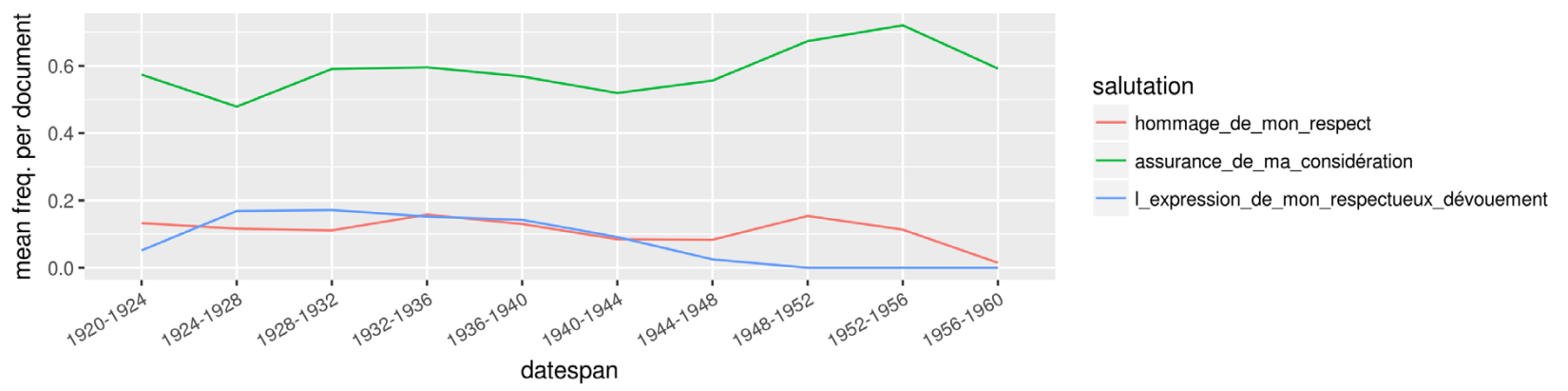

Figure 7: Evolution of final salutations.

'Ministre absent from the dictionary.

The value judgements of FEEL's authors raise questions and concerns. Some appear as a mere result of an automatic translation. The English term sdate`, for instance, is correctly translated to sdate in French, but the many dates mentioned in our corpus hardly carry any romantic connation; its association with joy is a mere misunderstanding. Similarly, an English 'person` is correctly translated to spersonne`, but the lemma then also means ınobody`. >Occupation ‘ has twofold meaning both in English and French and is distinguished in German by the terms Beschäftigung and Okupation. Polysemy is a great challenge to sentiments analysis. So is context. The most >disgusted report $^{71}$ of our preliminary analysis turned out to be an account for the total revenues from tobacco sales in Cuba in 1924, due to the fact that the FEEL dictionary associates >cigarettes striking, however, are the aforementioned value judgements. Some word markings of FEEL, respectively of NRC-Emolex, reflect a pro-religious and homophobic posture. To the discharge of its compilers, we retain that the lexicon results from crowdsourcing, i.e. from the current Zeitgeist of the English-speaking world. History might, some day, treat sentiment lexica themselves as historical documents.

Our aim being to analyse the evolution of sentiments of levels 1 and 2, we have individually examined the 100 most frequent lemmas for each polarity and for each one of the six Ekman emotions and removed all terms of level 3 that reflect judgement values of the lexicon's

\section{Politeness and sentiment}

Finally, as expected, we have observed that $20^{\text {th }}$ century ambassadors make extensive use of elaborate greetings and expressions such as 'j'ai l'honneur de`, ,veuillez agréer l'hommage de mon respect‘, 'votre excellence and, most frequently, sassurance de ma considération (18,488 occurrences).

Such turns contain words charged with sentiments of level 1 (respect, honneur, considération) but actually reflect mere adherence to social conventions. It can be argued that all reflect a particular disposition of level 2: diplomatic politeness, whose degrees of emphasis may vary. Interestingly, the choice of terms evolves over time (Figure 7). A full analysis could be dedicated to this topic, since even the slightest variations in polite wordings may carry otherwise unexpressed sentiments of joy or anger. At the present stage, however, we have combined such expressions into compound n-grams without emotional value.

\section{Sentiment scores and their global distribution}

In textual statistics, simply measuring the proportion of lemmas associated with a specific sentiment is not enough. The FEEL lexicon associates more of its terms with positive feelings than, for instance, with the negative ones. This unequal distribution would induce a strong statistical bias, since counting occurrence of lemmas associated with each sentiment would reflect the relative frequencies of sentiments in the lexicon itself, not their relative frequencies in a given text. The 


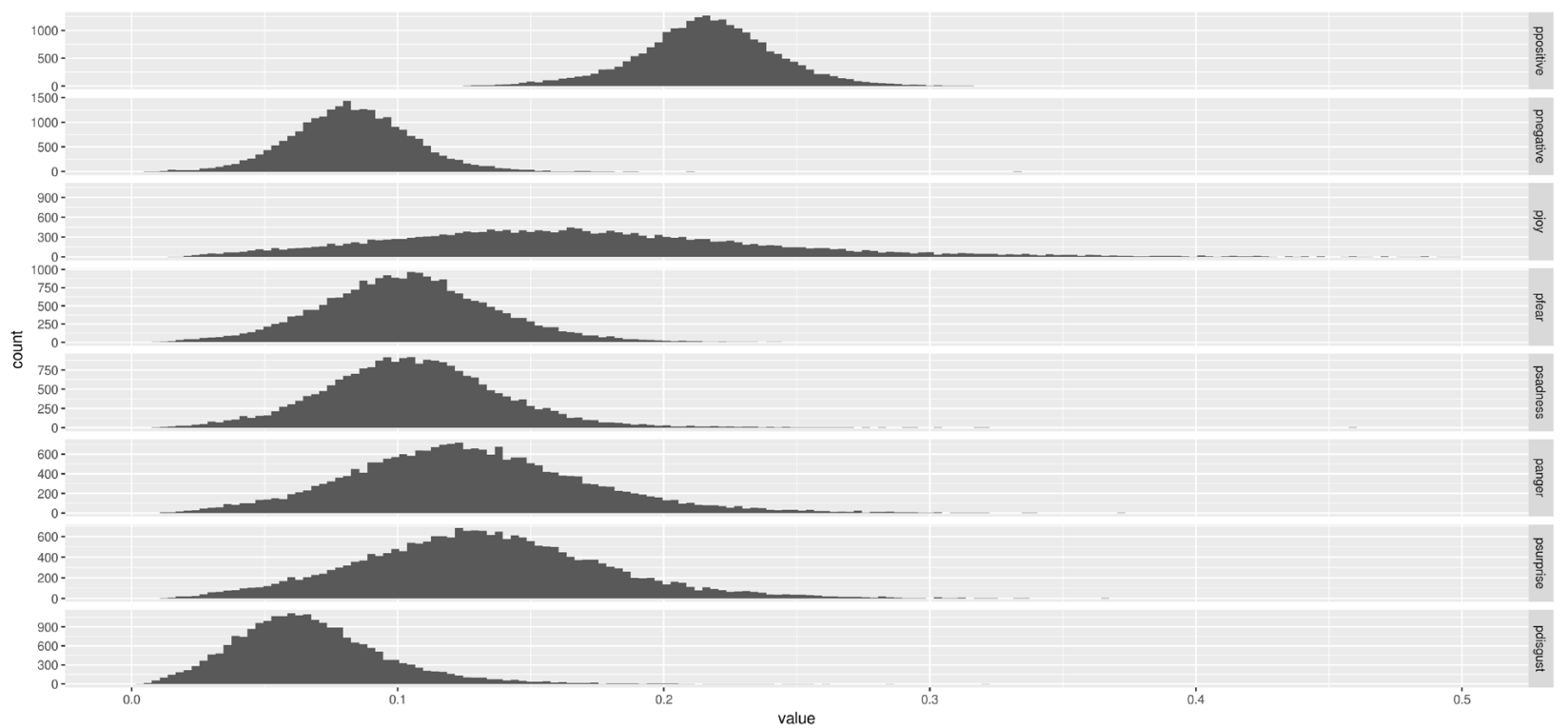

Figure 8: Number of texts expressing each given sentiment. Histogram. $n=27,000 .^{72}$

sentiment scores (e. g. $\mathrm{S}_{\mathrm{p}}=$ Score $_{\text {positive }}$ or $\mathrm{S}_{\mathrm{n}}=$ Score $_{\text {negative }}$ ) are therefore adjusted as follows:

$S_{p}=\frac{T_{p}}{T_{\Downarrow} L_{p}}$

$S_{n}=\frac{T_{n}}{T_{\sharp} L_{n}}$

where:

- $T_{p}=$ count of all positive tokens in a given text

- $T_{n}=$ count of all negative tokens in a given text

- $T_{\forall}=$ count of all tokens in the text

- $L_{p}=$ count of all lexicon entries marked as positive

- $L_{n}=$ count of all lexicon entries marked as negative

We have applied the same adjustment to all six Ekman emotions. A compound indicator taking into account both positive and negative polarities is defined as

compound $=S_{p}-S_{n}$

In the upcoming graphics, $S_{p}$ shall be referred as positive and $S_{n}$ as negative.

For the sentiment scores thus defined, we observe a normal distribution across texts, with varying mean values and standard deviations (Figure 8). This is encouraging for a statistical interpretation of our results.

The expression of positive sentiments dominates, followed by joy and surprise. The least proportion of texts expresses negative sentiments and sentiments of disgust.

\section{Global Results and Interpretation}

\section{Sentiment groups}

We present our detailed results in the section Individual cases،. Globally, we observe that sentiments can be organised into three groups. The first two, negative sentiments (negative, anger, fear and sadness) (Figure 12) and positive sentiments (positive, compound and joy) (Figure 20), display strong intragroup correlation. This means that an analysis in terms of positive and negative polarities is adapted for our purpose, and we shall concentrate on it in further work. In other words, in our context, the Ekman emotions mainly explicate the meaning of these polarities, without yielding more differentiated insight. Joy should be considered a heightened and probably more subjective positive emotion. Anger, fear and sadness combine into a general negative feeling. The third group, encompassing sentiments of disgust and surprise (Figure 19), shall be treated very briefly. 


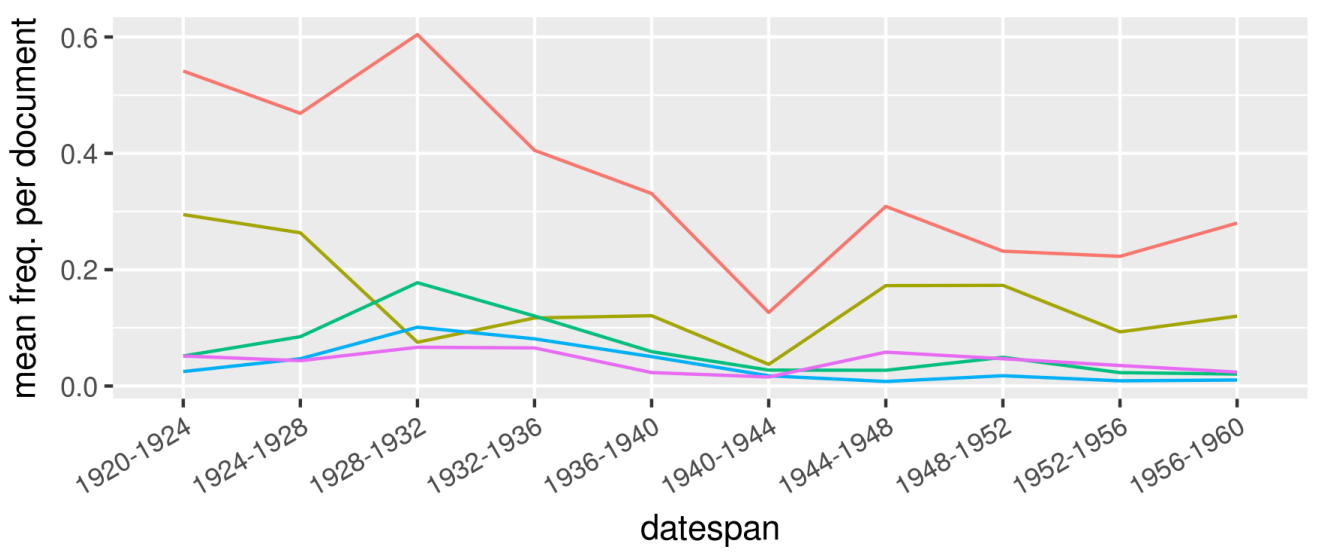

lemma

— crise

- grève

— chômage

— chômeur

— inflation

Figure 9: Evolution of mean document frequency of crisis-related lemmas.

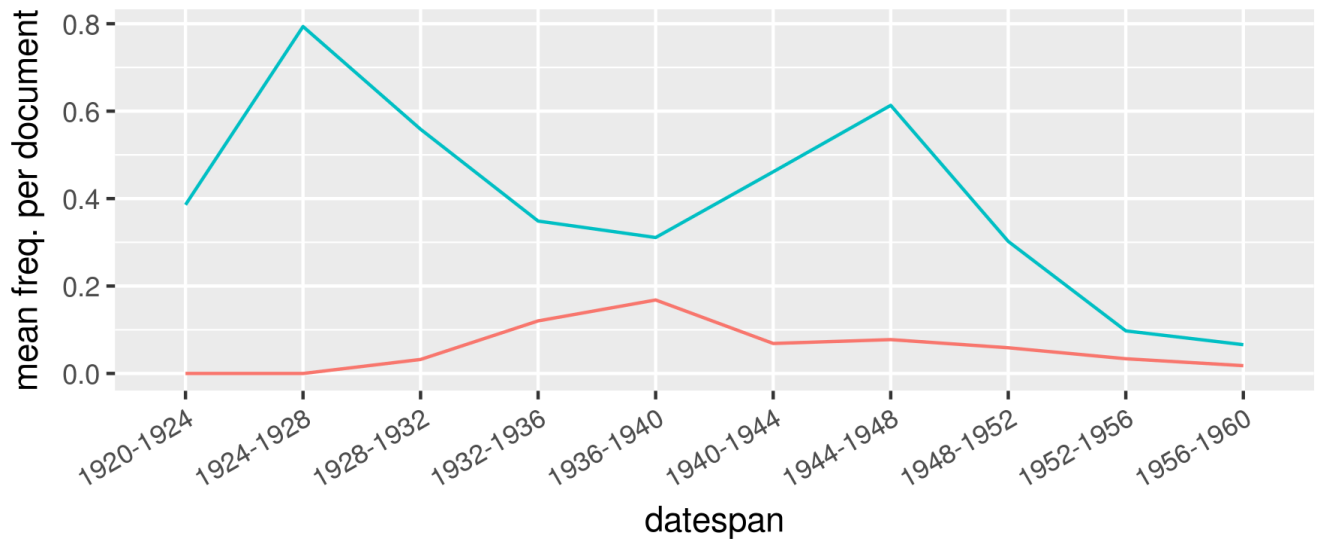

lemma related to

- nazisme

- fascisme

Figure 10: Evolution of mean document frequency of Fascism- and Nazism-related lemmas. These encompass nazisme, nazi, naziste, antinazisme, fasciste, fascisme, fascisation and anti-fasciste.

\section{The historic background}

Before all interpretation, we need to set our results against a general historic background. The major known events between 1920 and 1960, most of which verify by text mining of our corpus, include the world economic crisis in the late 1920s (Figure 9), early Fascism, later Nazism in the 1930s (Figure 10), the Second World War and post-war economic reconstruction (Figure 11) and the beginning of the Cold War in the 1950s. For the US, the evolution of the mood was different: Fascism and Nazism did not directly affect Washington until the 1940s when the US supported the Allies and entered the war, and post-war economic development took a different course than that of war-torn Europe, whose reconstruction was funded significantly by the US under the Marshall Plan. On the other hand, the highly industrialised Japan, politically part of the Axis powers, was presumably subject to similar basic moods as Europe. ${ }^{73}$ Japan suffered similar devastation during the war as Europe did, worsened by the atomic bombings of Hiroshima and Nagasaki, in addition to the shame about the defeat and occupation of the country by the Americans.

\section{The theoretical background: places as synthetic subjects of sentiments}

In psychology, the usual subjects of emotions are human individuals, observed in a precise moment. In our case, we are dealing with aggregate emotions of entire sets 


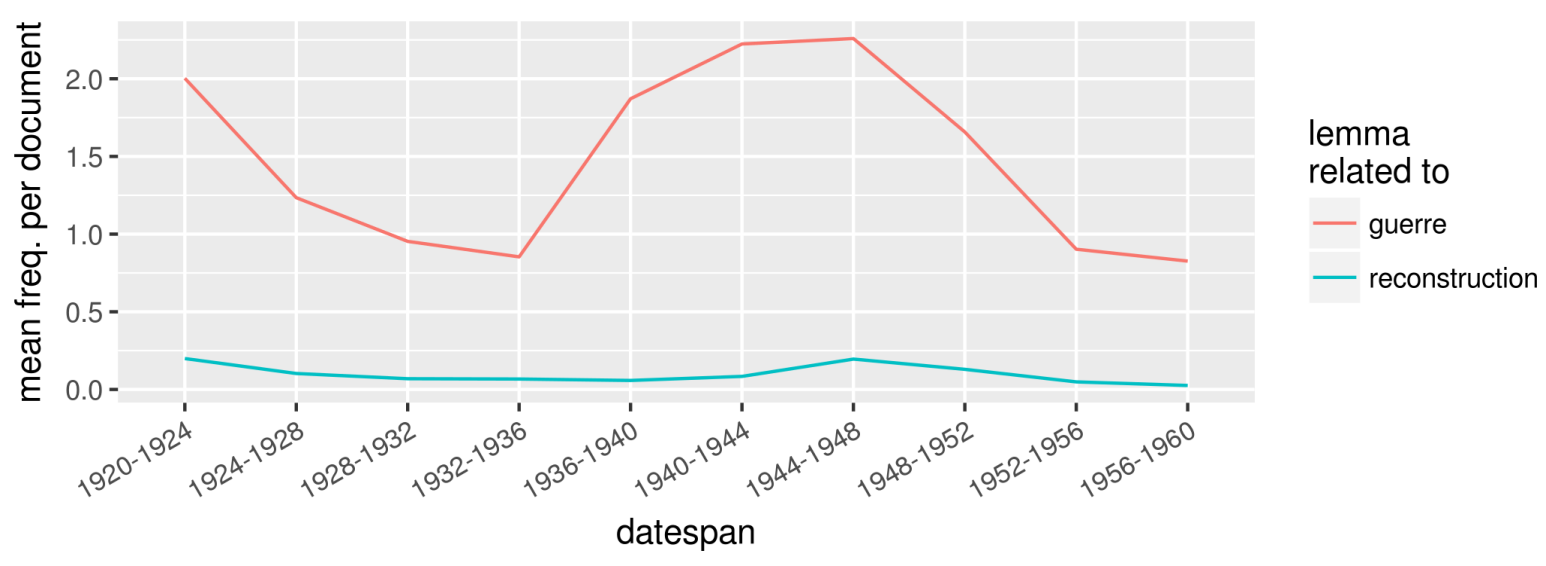

Figure 11: Evolution of mean document frequency of terms related to war and reconstruction, including reconstruire and régénérer.

of political reports, written by multiple authors at different dates. The ontological gap between parts and the whole that we cross in this manner requires caution. While we do provide excerpts of individual political reports to support our detailed analysis, the reader must keep in mind that no single text can fully illustrate the aggregate phenomenon of a statistical regularity. Expecting the contrary would resemble predicting a human's behaviour from the observation of his or her individual cells.

We argue that aggregate subjects of emotions do exist. In fact, as we have discussed in earlier work, the acting subject of any action, including sentiment expression, is always a synthetic individual. ${ }^{74}$ In our case, we aggregate reports based on the place and time of writing. Sentiments expressed by these sets of political reports are the sentiments of these sets, not sentiments of isolated documents and, a fortiori, not sentiments of an isolated author. Even at a single report level, the sentiment of a document is the result of a particular synthesis of:

- a human author

o selected as ambassador for particular abilities by an institution

- representing Switzerland

- having its own interests

- representing interests of third parties (19391945)

o consciously writing to that institution

- of which he possesses an own inner representation o assisted by a personnel producing text drafts and modules

- a given context of writing

0 in a given place

- in which the author has been living for $1-3$ years $^{75}$

0 at a given time

- marked by a set of current geopolitical concerns

- a specific subject matter

o identified as important by the author

0 that has triggered the writing of the report

The advantage of aggregating sentiments of multiple documents is that we progressively leave the level of subject matters and authors to find the aggregate sentiments of institutions, epochs and places, which are only revealed in the aggregate. This is all the more significant if we recall that the reports were sent regularly to the FDFA in Berne serve to inform the government about the international situation and thus are the basis for making foreign and security policy decisions, acting not as an individual but as a nationstate. The reports permit feeling like a state. ${ }^{76}$

Throughout the history of the administration, synthetic sentiments translate into synthetic actions. This process gives a nice illustration of the old notion of Wirkungszusammenhang, ${ }^{77}$ more recently reappeared under the terms of agencement (assemblage) in the Deleuze and Guattari's writings on Kafka. ${ }^{78}$ 
Thus, the earlier mentioned stance, according to which "the person shapes the activity « ${ }^{79}$ might hold, but only insofar as we keep in mind that the activity and its context also shape the person. All individuals, be the aggregate or personified, are the result of synthesis.

In our case, a fourth, easily forgotten actant intervenes:

- the sentiment lexicon itself

o produced by a specific scientific method

- applied to a specific set of data

- produced by human actors

o embedded in a specific epoch and cultural context

- partially verified by a set of human actors

- embedded in a specific epoch and cultural context

o translated by a machine

With regard this fourth actant, we must stress to which point word-sentiment associations strongly vary with the selection of a lexicon's contributors. Our manual adjustment of the FEEL lexicon seeks to limit observation to sentiments proper to subjects of levels 1 (author and subject matter) and 2 (context and institution).

The relation between the three subject levels of sentiment expression and the synthetic subject

As suggested, there is a direct correspondence between our fourth actant and sentiment expressions of level 3 (judgement arbitral of the lexicon's authors). What we have defined as level 1 (ıjoie`, >tristesse`, etc.) and 2 ('guerre`, ‘crise`, etc.) of sentiment expression could allow us to distinguish the part played by single human authors in the synthesis of sentiment scores of documents or document aggregates. Methodologically, however, making this latter distinction would imply a total revision of the more than 10,000 terms of the FEEL dictionary, which we could not accomplish at this stage; thus, our sentiment scores do not account for it. We shall keep track of these levels, however, in our interpretation of individual cases.

\section{Individual cases}

For an interpretation of the quantitative analysis of the political reports, we have selected six countries, respectively capitals: Great Britain (London), France
(Paris), Italy (Rome), Sweden (Stockholm), Japan (Tokyo) and the US (Washington). This allows us to analyse cities on three continents, while concentrating on locations from where records are available with sufficient dating precision for the whole time of observation (cf. Figure 4). We start with negative sentiments.

\section{"Negative« sentiments}

A first general observation shows that the range of negative feelings before and after World War II is significantly smaller than that during the war. Their frequency reaches its maxima between 1940 and 1944. Mathematically, this can be due to either a frequency decline in positively connoted lemmas or a frequency rise in the negatively connoted ones. Historically, we assume that it relates to anxiety and the negative horizons of expectation during wartimes.

Figure 13 gives better insight into rise of negative sentiments in the 1940-1944 period, by showing the obvious contribution of the negative lemma suerres

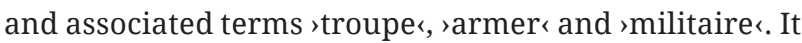
is striking that, according to our three subject levels of emotional expression defined earlier, the most influent sentiments cannot be attributed to the level of authors' reports (1) but to the level of political entities (2). This does not mean that the ambassadors never express personal-level sentiments, as illustrate documents found for Tokyo. TSA allowed us to detect the most negatively marked text from that Embassy (or Legation, as an Embassy was called then). It was headed by Camille Gorgé, a lawyer and the Envoyé extraordinaire et ministre plénipotentiaire of Switzerland in Japan..$^{80}$ In his telegram No 476 on 29 December 29 1944, he let the Foreign Ministry in Berne (the Federal Political Department, as it was called that time) know that Japan ends badly (»finit mal«): People [are] deprived of everything without illusions ("peuple privé de tout sans illusions«); they are suffering from hunger and cold ("souffre de la faim et du froid «). The ambassador describes the economic situation [as] still lamentable ("situation économique toujours lamentable») and the increased discomfort due to train traffic disruptions caused by aerial bombardments and recent earthquake ("malaise accru par perturbations du trafic ferroviaire 


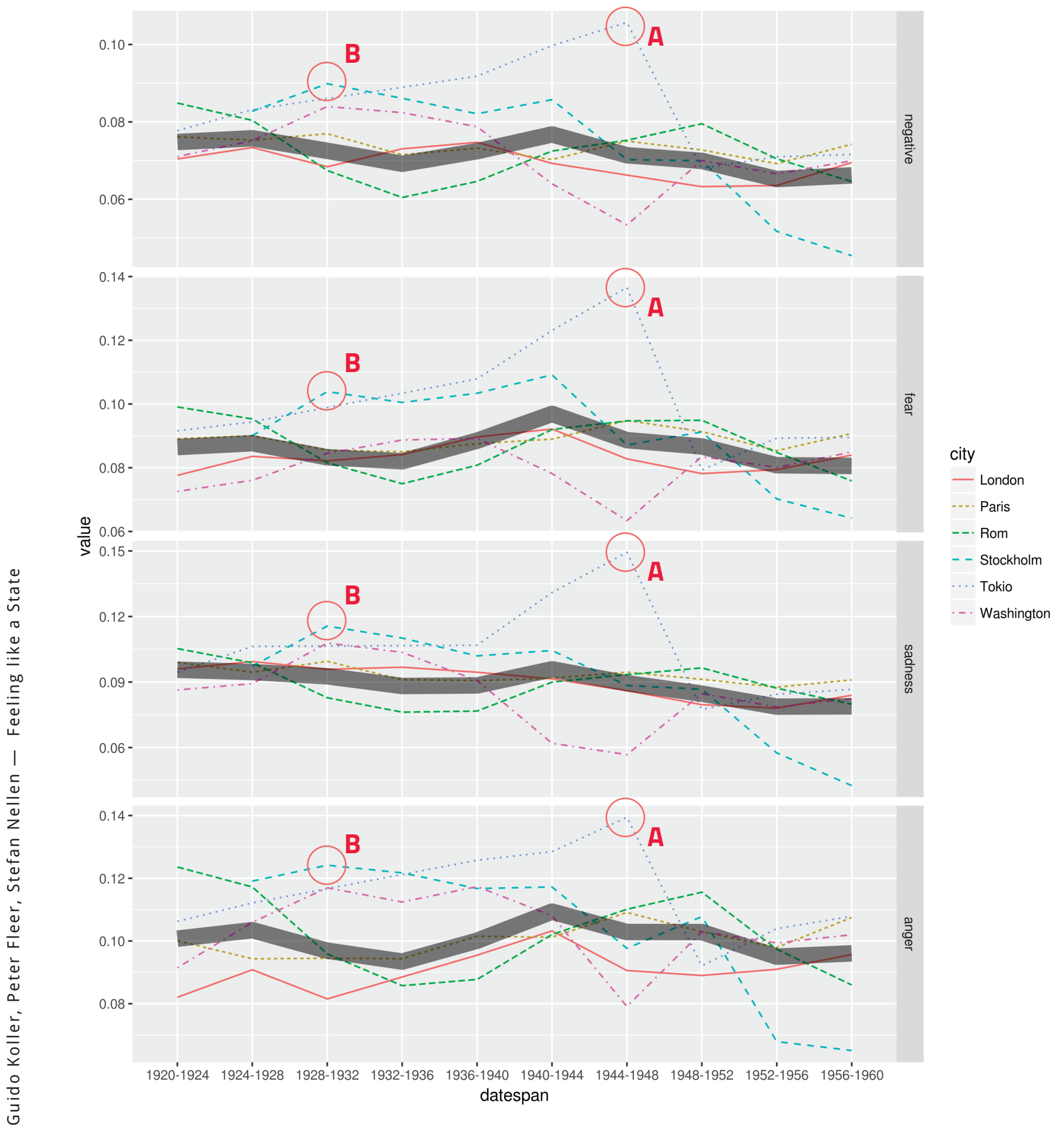

Figure 12: Indicators of negative sentiments: negative, fear, sadness, anger. The thick grey line reflects average of all cities shown in Figure 2 and Figure 3. Annotations: maximum Tokyo (A) and maximum Stockholm (B). 


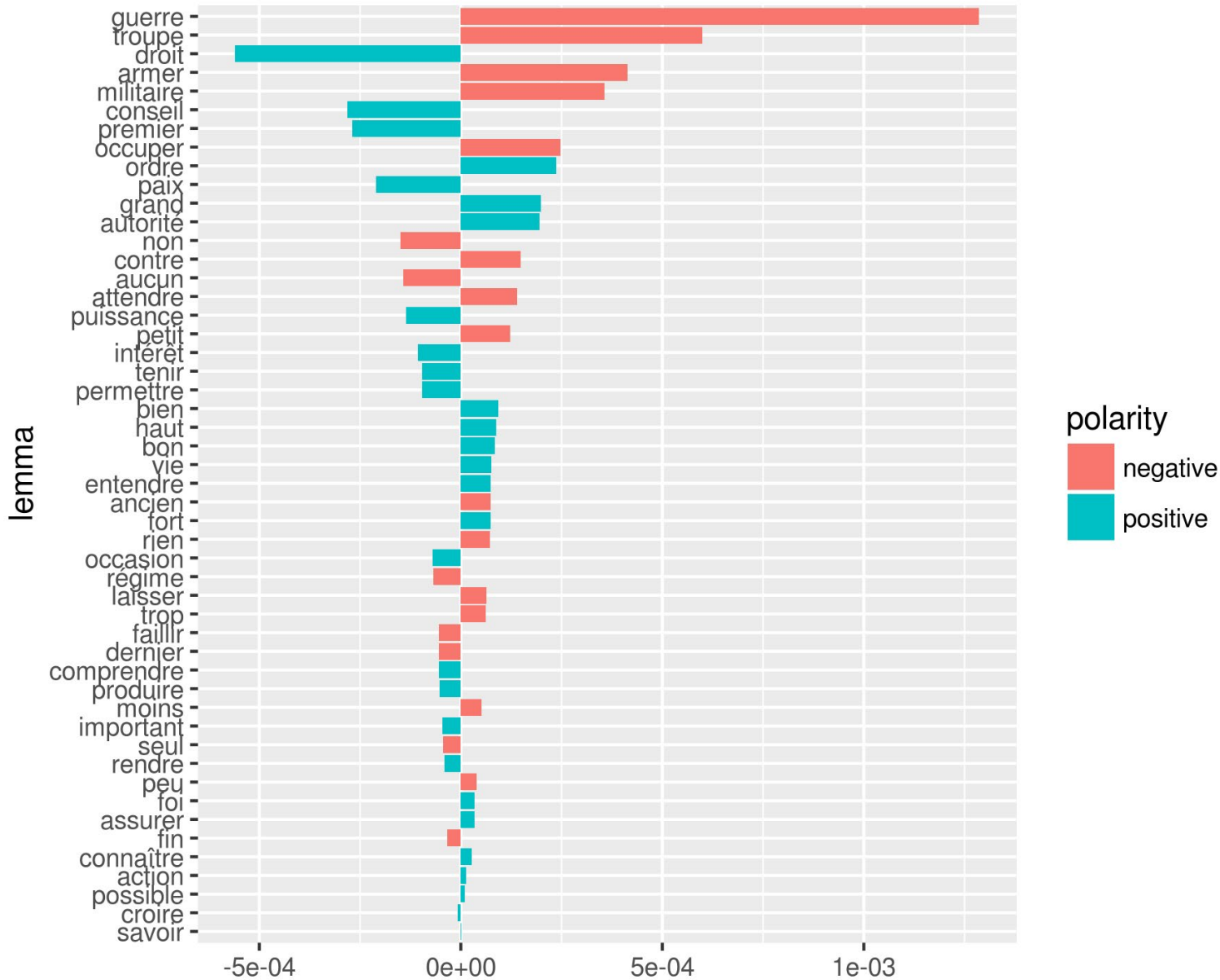

Figure 13: 50 polar lemmas with the largest D between 1940 and 1944 frequencies and all time frequency average. Polarity is given by colour. Negative values on the $x$-axis denote terms that appear less in that period than in all time average, and positive values represent terms that appear more.

causées par bombardements aériens et récent tremblement de terre«). But not only the American bombardments from the air test the population (»raids aériens éprouvent la population «) but also the hope for a victory of the Axis powers dwindles: The defeat seems inevitable (»défaite semblant inevitable«). ${ }^{81}$

Nine months later, on September 1945, after the defeat of Japan, Gorgé sent a telegram to Berne, which was also very emotional; it reflects Japan's sadness. The Swiss ambassador reports on his meeting with the new foreign minister: He has not much illusion about the difficulties for Japan to win back international esteem (»Il ne se fait pas beaucoup d'illusions sur les difficultés pour le Japon de reconquérir l'estime internationale«). The position of the government is extremely precarious du gouvernement est d'ailleurs extrêmement précaire car elle dépend entièrement des américains«). Gorgé is amazed at the ease with which the Japanese suffer their extremely humiliating fate (»On est toujours plus étonné de la facilité avec laquelle les japonais subissent leur sort extrêmement humiliant «). ${ }^{82}$

Relating back to the question of the subject of emotion (author or political entity), ${ }^{83}$ we are clearly situated on the level of the individual. Several factors explain the elevated indices of negative emotions in end-of-war Tokyo. First of all the extreme conditions, of course, though similar ones have not lead envoys in other war-torn cities of that time to a comparable passion. More decisive seems Gorgé's ability and willingness to express sentiments, induced by a specific culture of the French-speaking diplomats of 1920s and 


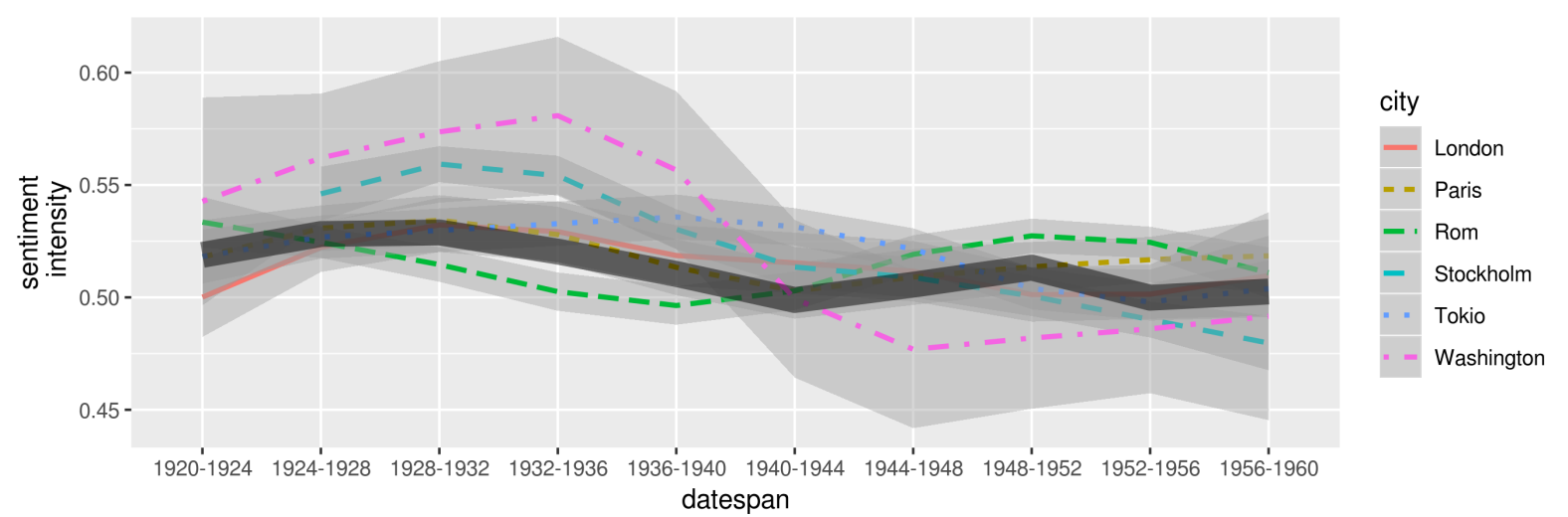

Figure 14: Evolution of sentiment intensity defined as (positive + negative)/total of tokens excepting stopwords. Loess smoothing applied. Global average in thick dark grey.

1930s versed in art and literature..$^{84}$ That TSA allowed us to detect Gorgé's texts, without prior knowledge about his career, could have an interesting explanation. As stated in our introduction, TSA is notably developed in literature science. Its detection of sentiments relies on the extensive use of adjectives, adverbs and emotionally coloured substantives; such are less frequent in a more cautious writing, which might, nevertheless, express emotion by circumlocution and understatement that fall under the radar of current TSA methods. A hypothesis attested by the global decline of the proportion of sentiment-marked lemma (Figure 14) is that the professionalisation of Swiss diplomacy has reinforced such cautious language, modifying the remotional habitus ${ }^{85}$ of its members. Further inquiry in this direction shall consider the proportion of adjectives, adverbs and lemmas with a high subjectivity classification (cf. supra), as well as the global convergence of these values across different embassies.

These observations raise many questions: To what degree do an ambassador's personal feelings influence relations between political entities in general and between Japan and Switzerland specifically? Gorgé probably identified too strongly with his host country, which might explain why he had to leave Japan and was sent to Turkey in $1946 .{ }^{86}$

But let us proceed to a second example, in which the aggregate level of the political entity becomes more apparent. Surprisingly, the document with the most violent rash in terms of negativity, fear, grief and anger is a report on Sweden from the 1928 to 1932 movements in Sweden in the late 1920s and 1930s in comparison to other Western countries, ${ }^{87}$ something that seemed to disturb Swiss diplomacy deeply.

Switzerland and Sweden had a long tradition of good relations. Since 1847, the Swiss consulate in Christiania (Oslo) was also responsible for Sweden. The first Swiss consulate in Sweden was established at Stockholm in 1887. For a longer time, the head of the Swiss diplomatic mission in Berlin was also responsible for Sweden. The diplomatic relations were upgraded in 1919 with a Swiss envoy to Stockholm. In 1957, the legation was transformed into an embassy. The two countries made similar experiences during the World War II: Both were neutral, both economically and financially dependent on relations with both the Allies and Nazi Germany. The Allies even addressed common questions in a SwedenSwiss Committee. As Sweden and Switzerland faced new challenges during the Cold War, the two countries moved even closer. Foreign Ministries agreed on a regular mutual exchange of views in the 1950s. ${ }^{88}$

The cultural relations between Switzerland and Sweden were close as well. Schiller's William Tell was translated into Swedish in 1823. Both countries exchanged films during the war. In Switzerland, Swedish lifestyle (home furnishing, books, travel) became very popular after World War II. In Sweden, Switzerland was sometimes seen as a model for the future constitution of Europe, ${ }^{89}$ whereas in Switzerland, many thought Sweden to be a modern model society.

Given this narrative of the tight and good relations between both countries, it astonishes that the document 


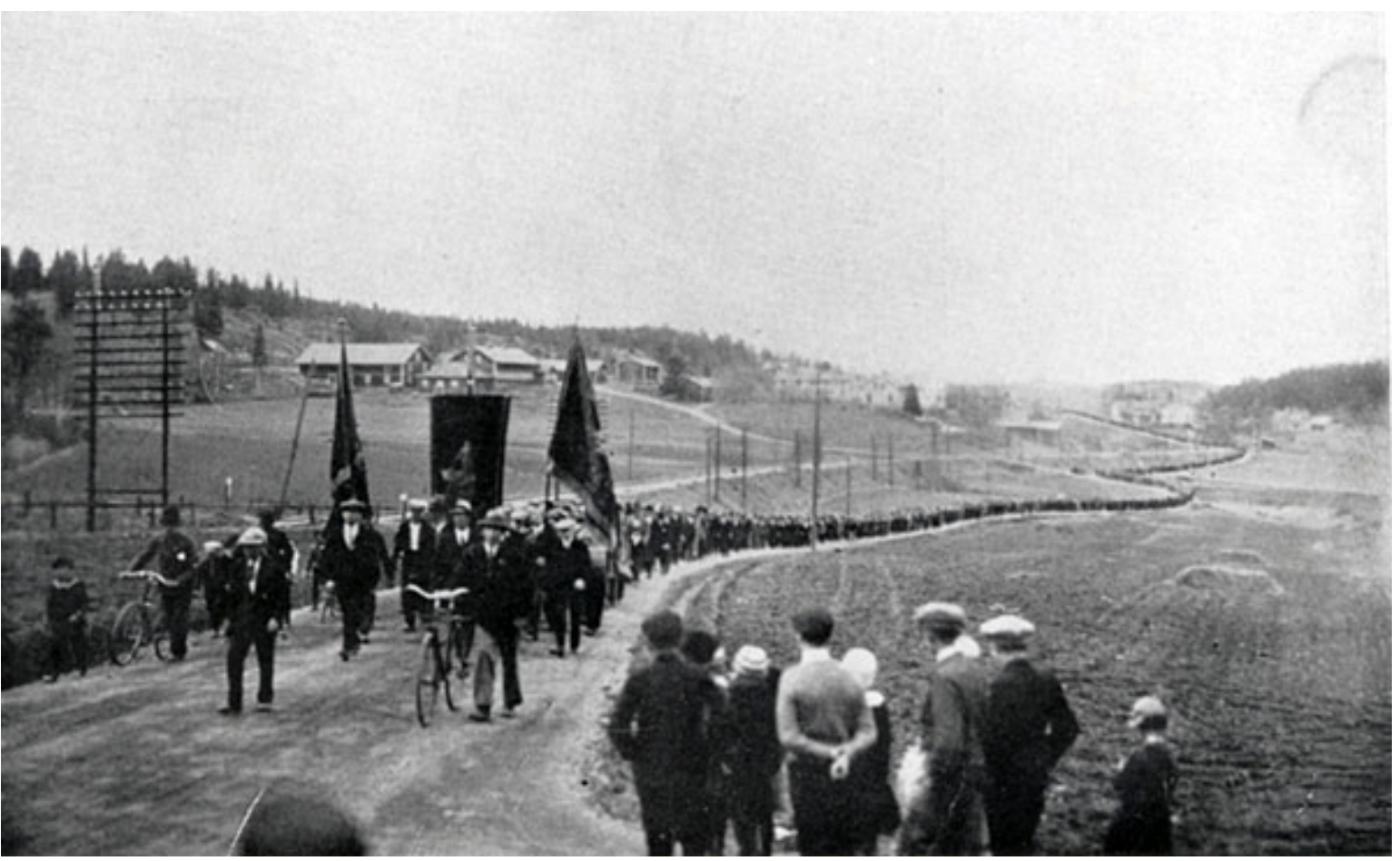

Figure 15: Demonstration march against strike-breakers in Ådalen, Lunde, on May 14th 1931, 3PM, gathering 3,000 people. A few minutes later, five people were killed by bullets fired by troops. Photo: IT News Agency / Scanpix.

from our corpus with the second-most violent rash in terms of negativity, fear, grief and anger, after the Tokyo reports, is the aforementioned report ${ }^{90}$ on Sweden from the 1928 to 1932 period. Frequency D analysis for this period (Figure 16) shows a relative rise of negatively connoted lemmas such as crisis (`crise ‘), unemployment (`chomâge`), radical (`radicale`) and extreme.

Obviously, the negativity of the reports relates to an economic crisis. But what does the Swiss embassy in Stockholm deem as radical and extreme in this context? This question can be answered by representing the semantic network of word co-occurrence in the documents from that place and period (Figures 17 and 18). The figures show not only negative and positive expressions but also their neighbouring lemmas, notably ssocialiste`, souvrier,, scommuniste 'gauche`. Co-occurrent terms are connected by network edges and closer to each other. Based on them, we can hypothesise that the strengthening of the labour movement in Sweden worried Swiss diplomacy. The Socialist Workers’ Party (`parti`, `socialiste`, ১ouvrier`) taking over government power in Sweden ('pouvoir`, did not follow politically and socially. This would also explain why, after World War II, Switzerland's idealised image faded and criticism became loud. Swedish authors like Arvid Brenner scourged in particular a reckless capitalism in Switzerland. ${ }^{91}$

\section{Disgust and surprise}

Disgust and surprise (Figure 19) mostly correlate with negative sentiments and provide no extra information. We see no specific added value of these sentiment categories - as implicitly defined by their associated word set in the FEEL lexicon - for the analysis of our dataset. Based on our observation, we do not recommend their use for analysis similar to ours.

\section{"Positive« sentiments}

One curve of evolution of the positive sentiments (Figure 20) immediately stands out: Values for Washington are falling sharply during World War II, remain at a very 


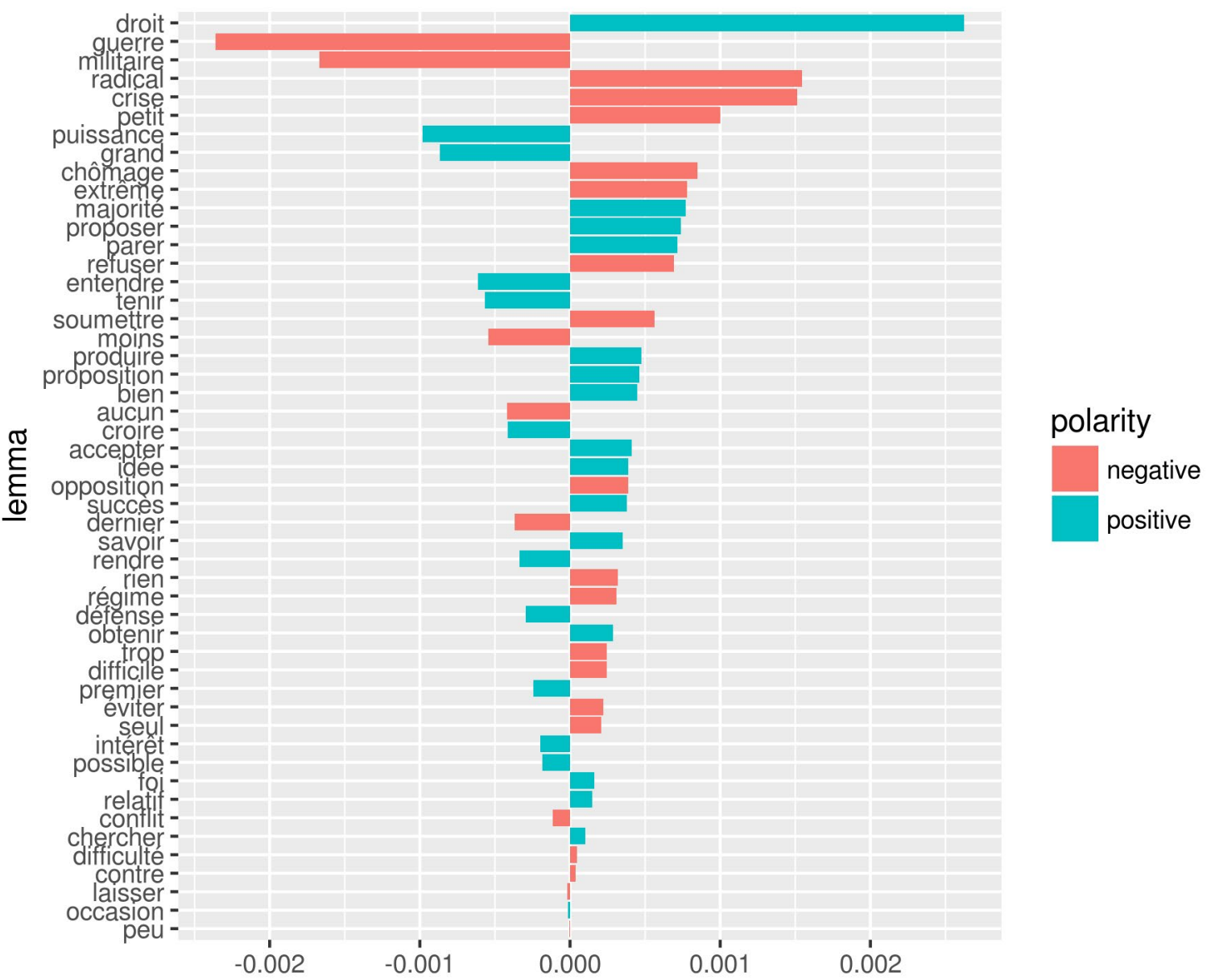

Figure 16: Stockholm. Frequency D of polarised lemmas between the 1928 and 1932 period and all time Stockholm average. Colour indicates polarity. Negative values on the $x$-axis denote terms that appear less in that period than in all time Stockholm average; positive values denote terms that appear more.

low level for a while and then rise again after the war (A). Lemmas such as >croire then (Figure 21), suggesting a loss of mutual confidence. Upon the background of historical knowledge, ${ }^{92}$ the interpretation seems quite simple: The Americans criticised Switzerland because of its close economic and financial ties to Nazi Germany. They blocked Swiss assets in the US and blacklisted Swiss companies. The tensions did not settle until 1946, when the Washington Agreement offered a basis for good post-war relations. The joy of this success of Swiss diplomacy seems visible in Figure 20. Yet, we did not find more specific terms related to these events in our corpus with text-mining techniques (Figures 9-11). We venture the suggestion that these events had a deeper, more ssubconscious، effect on the tone of the reports of the Swiss embassy in Washington: The more frequent use of negative turns involving words like >contre or `malgré might be a sign of this.

As much interesting are the joy scores for Stockholm that decline rapidly during the 1930s (Figure 20B), stay at a low level during the forties and decline again after the war (Figure 20C), almost in a mirrored image of the assessment for Figure 12. This points historians interested in relations between Switzerland and Sweden to possibly relevant sources for describing these relationships while socialist forces increasingly determined politics in Sweden. In addition, it raises a question similar to the case of Tokyo: To what degree do the Swiss ambassador's feelings influence relations 


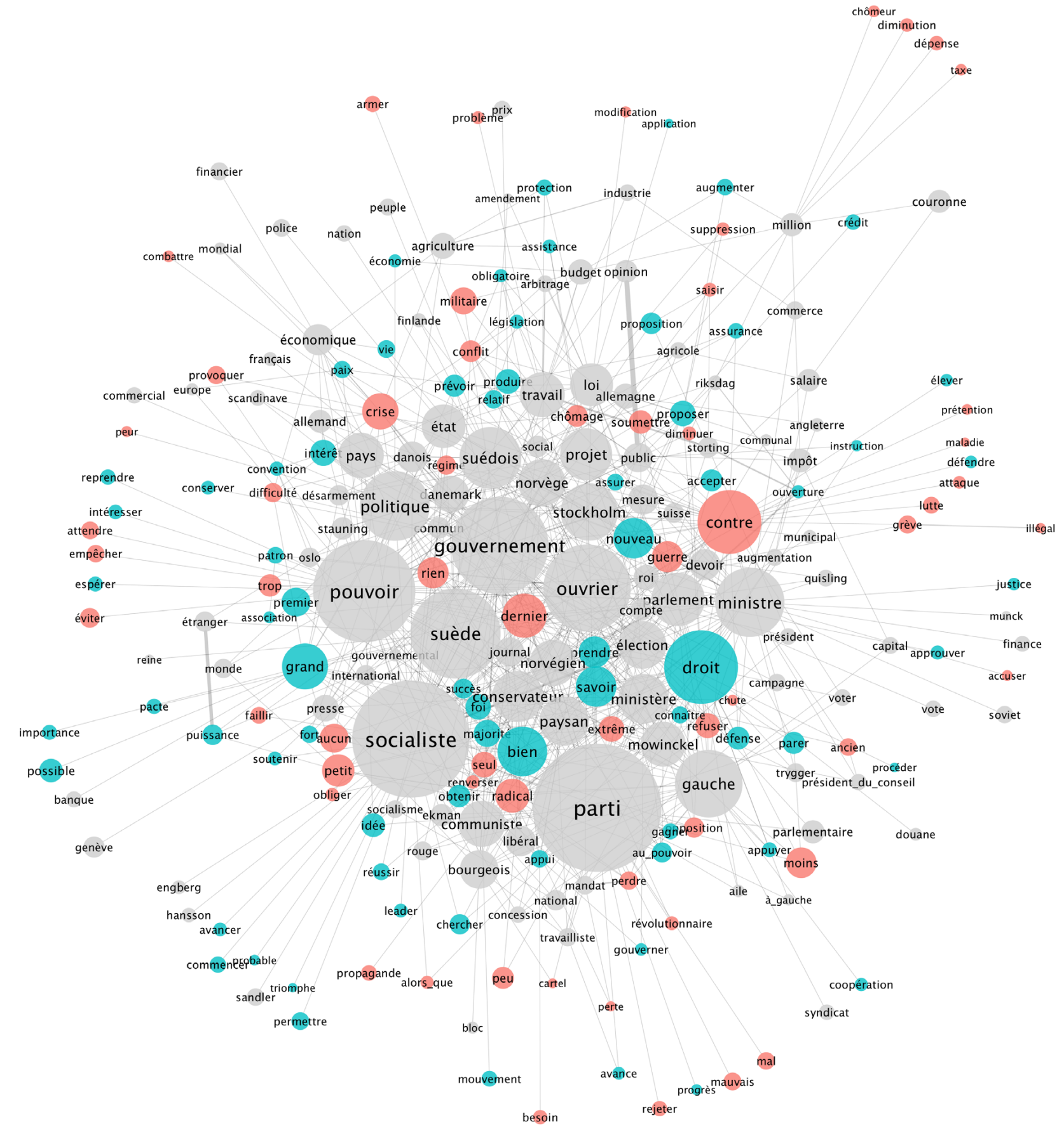

Figure 17: Co-occurrence network of most frequent lemmas in reports from Stockholm, 1928-1932. We have kept only politically relevant lemmas in this visualisation (excluding e. g. sannée` or svoirı). We applied Fruchterman-Reingold network layout, meaning that strongly linked lemmas are close to each other on the graphic. Edge weights show lemma co-occurrence frequency; circle sizes are proportional to lemma frequency. Polarised lemmas, marked in red and turquoise, reflect the sentiments expressed when reporting on these topics. 


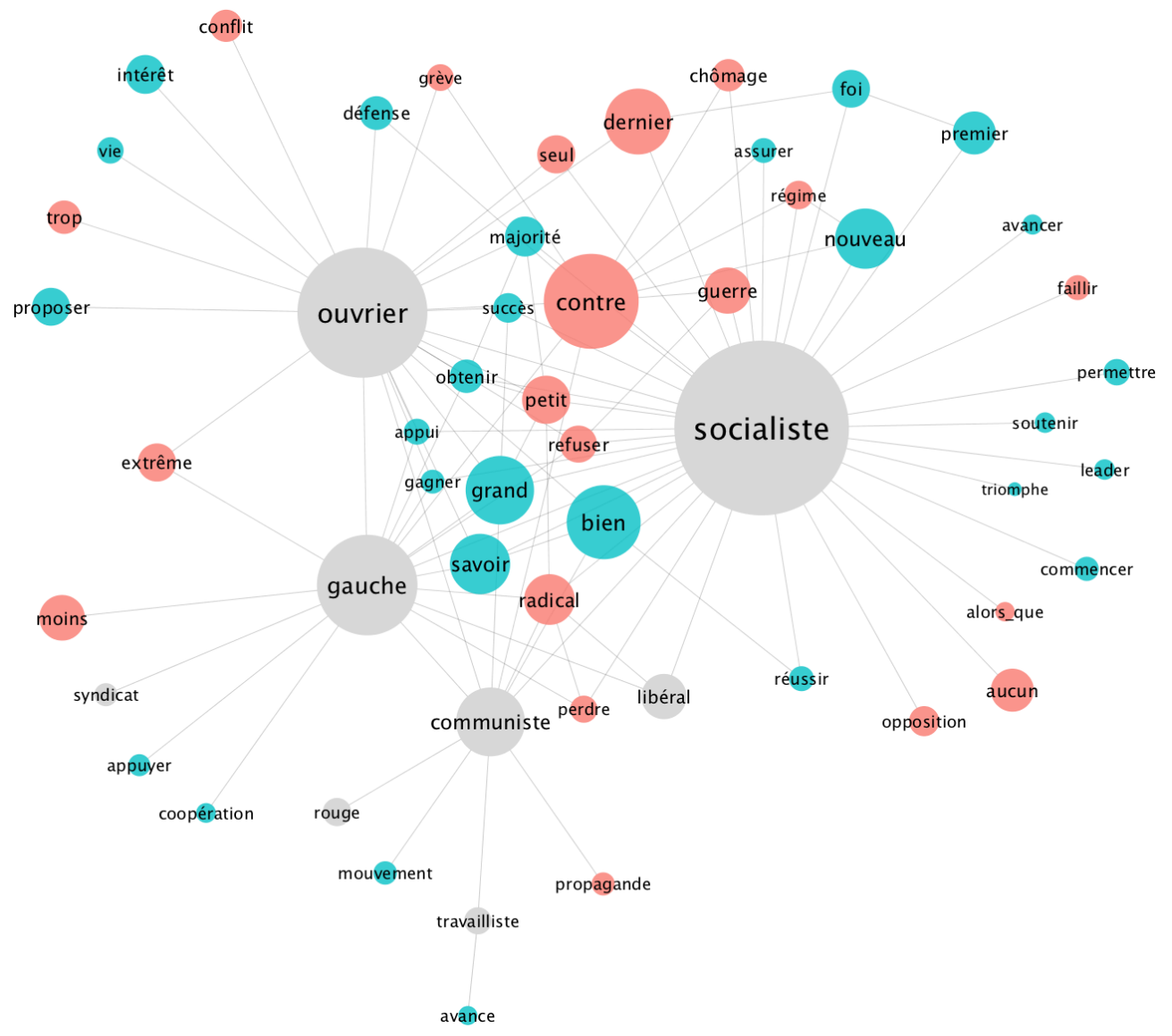

Figure 18: Selected nodes from the semantic network of Figure 17, showing only the part of the network related to social movements. Socialism and the working class movement are particularly important topics in this period.

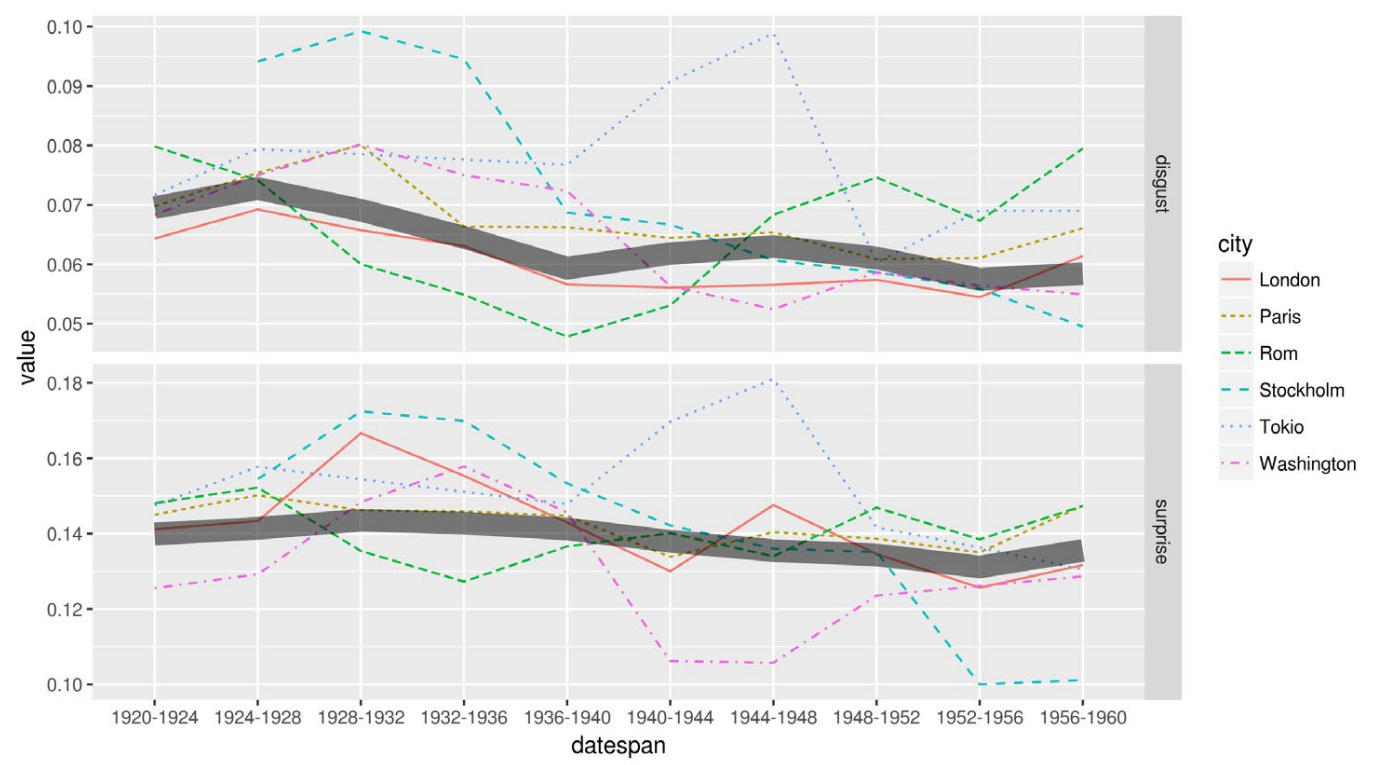

Figure 19: Indicators of disgust and surprise. The thick grey line reflects average of all cities shown in Figure 2 and Figure 3. 

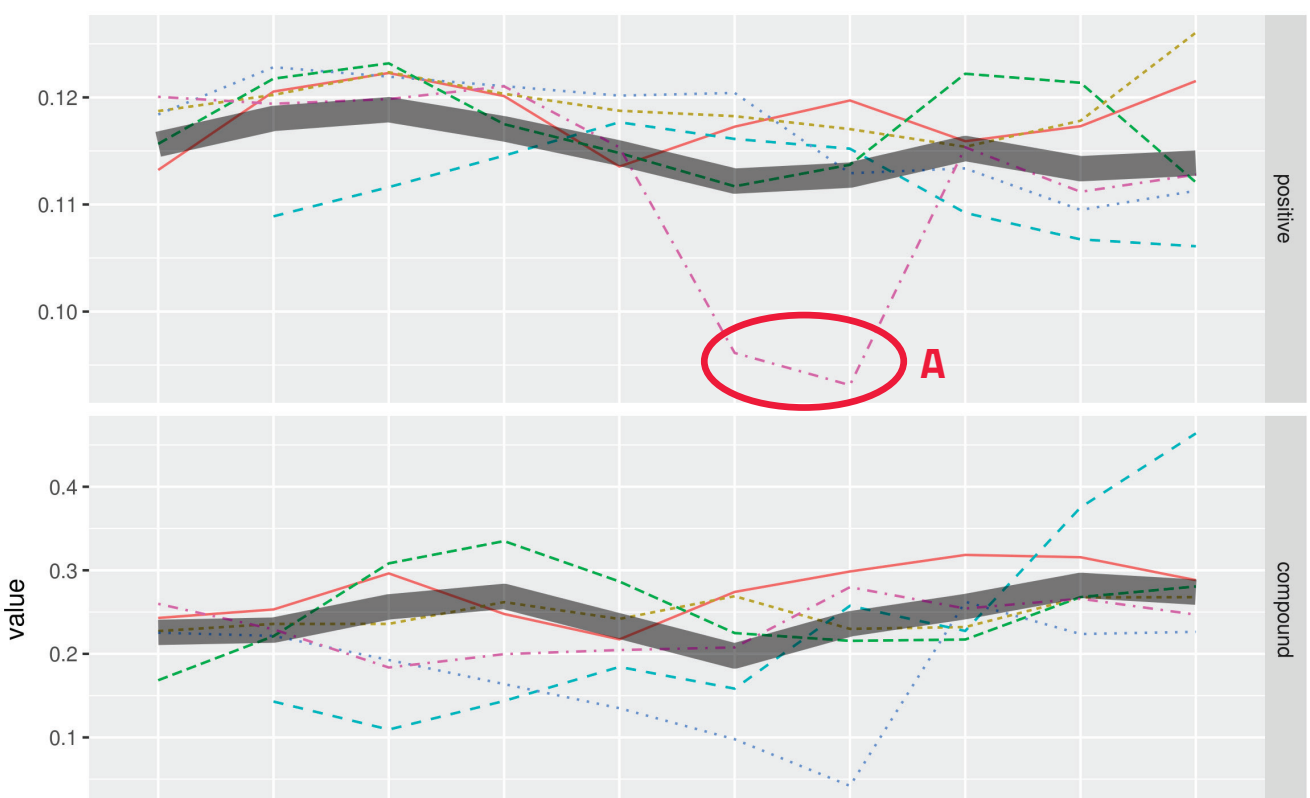

city

- London

.... Paris

$--\cdot$ Rom

- - Stockholm

Tokio

-. Washington

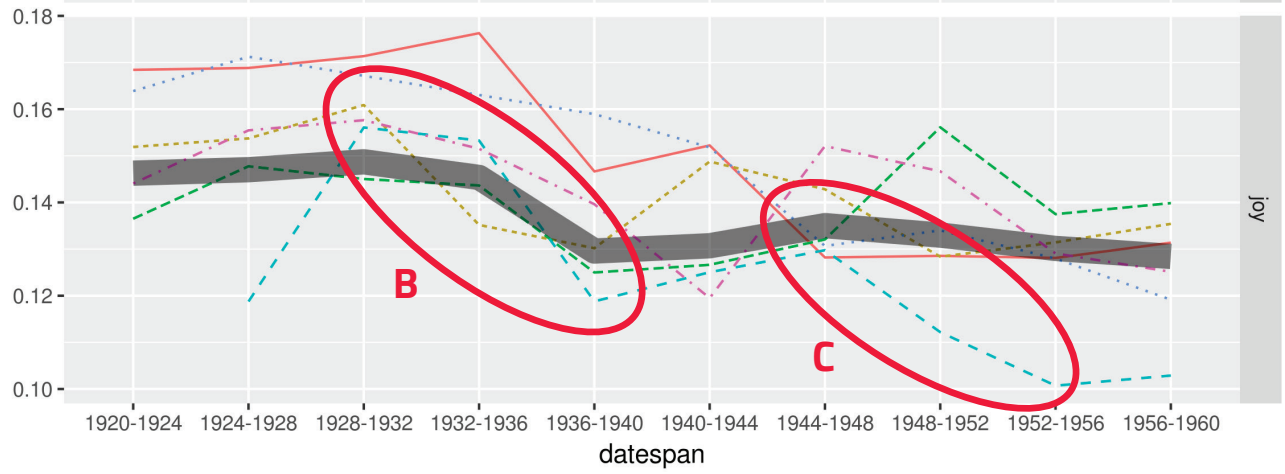

Figure 20: Indicators marking positive sentiments: positive, compound and joy. The thick grey line reflects average of all cities shown in Figure 2 and Figure 3.

between Sweden and Switzerland? What role did the socialist turn play in the reports for a country with which Switzerland felt strongly connected? Did the professionalisation of diplomacy improve these relations?

Positive sentiment scores for London are consistently elevated. The same applies to Paris and Rome. In effect, literature also attests for good relations between Switzerland and its direct geographical neighbours, France and Italy. ${ }^{93}$ Our results suggest that these relations were hardly affected by the French Vichy regime and the Italian fascist government. To verify this, historians could turn to the individual sources identified by the algorithms of the sentiment analysis something that we cannot do here.
In all cases, caution in such interpretations is important. It is, for instance, worth taking a closer look at the big joy in London (Figure 22). The terms that contribute to this result are notably good (ıbien`), create (`créer`), success, interest and beneficial ('favorable`). They could signal both good bilateral relations and a potentially favourable economic situation. To determine what was really meant, the individual reports should be consulted to answer more specific questions: When did the roaring 20s come to an end in the UK? How did this affect the bilateral relations with Switzerland, which in general remained rather consistently good? 


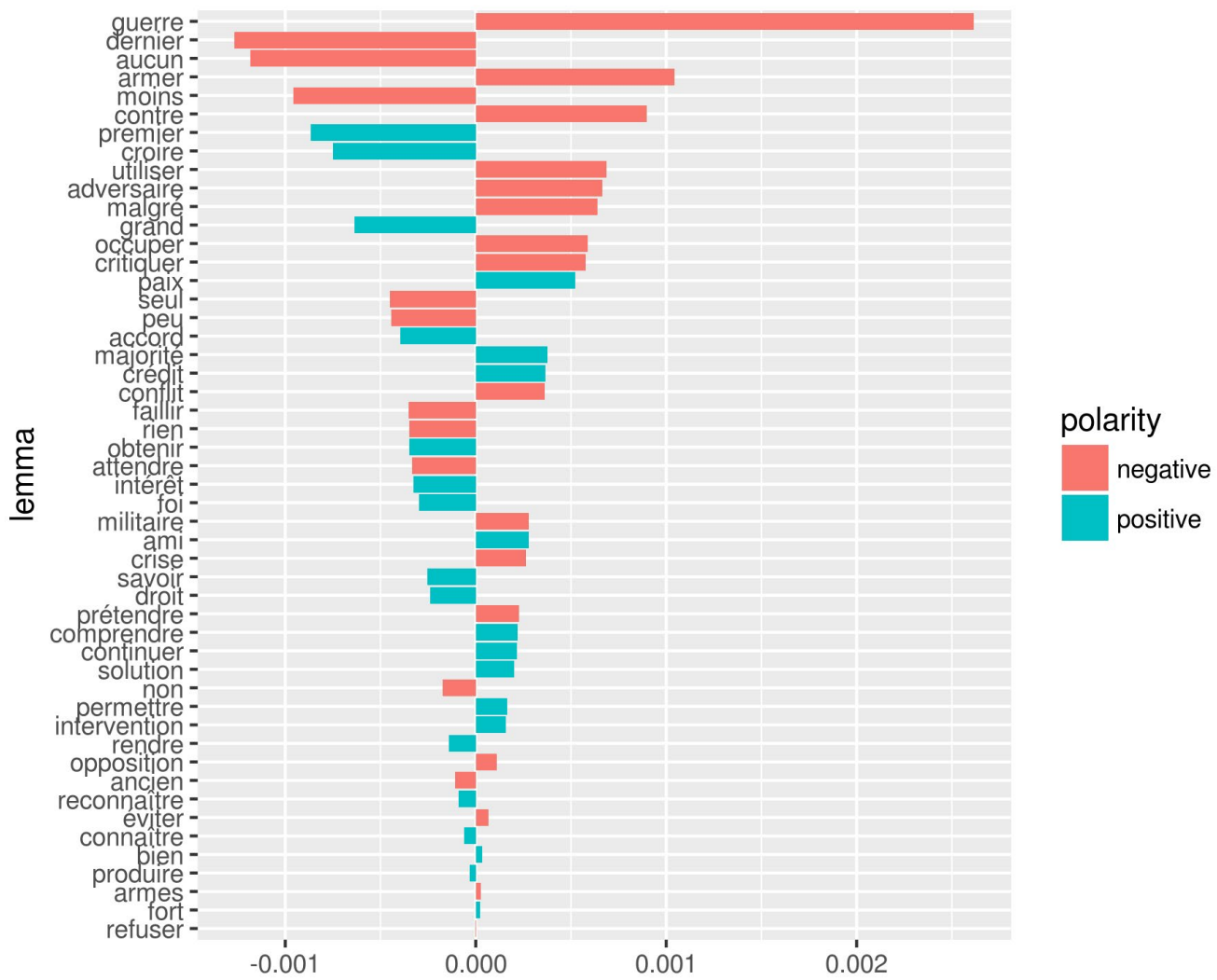

Figure 21: Washington. Frequency D of polarised lemmas in the 1940-1944 period and all time Washington average. Colour indicates sentiment polarity. Negative values on the $x$-axis denote terms that appear less in that period than in all time Stockholm average; positive values denote terms that appear more.

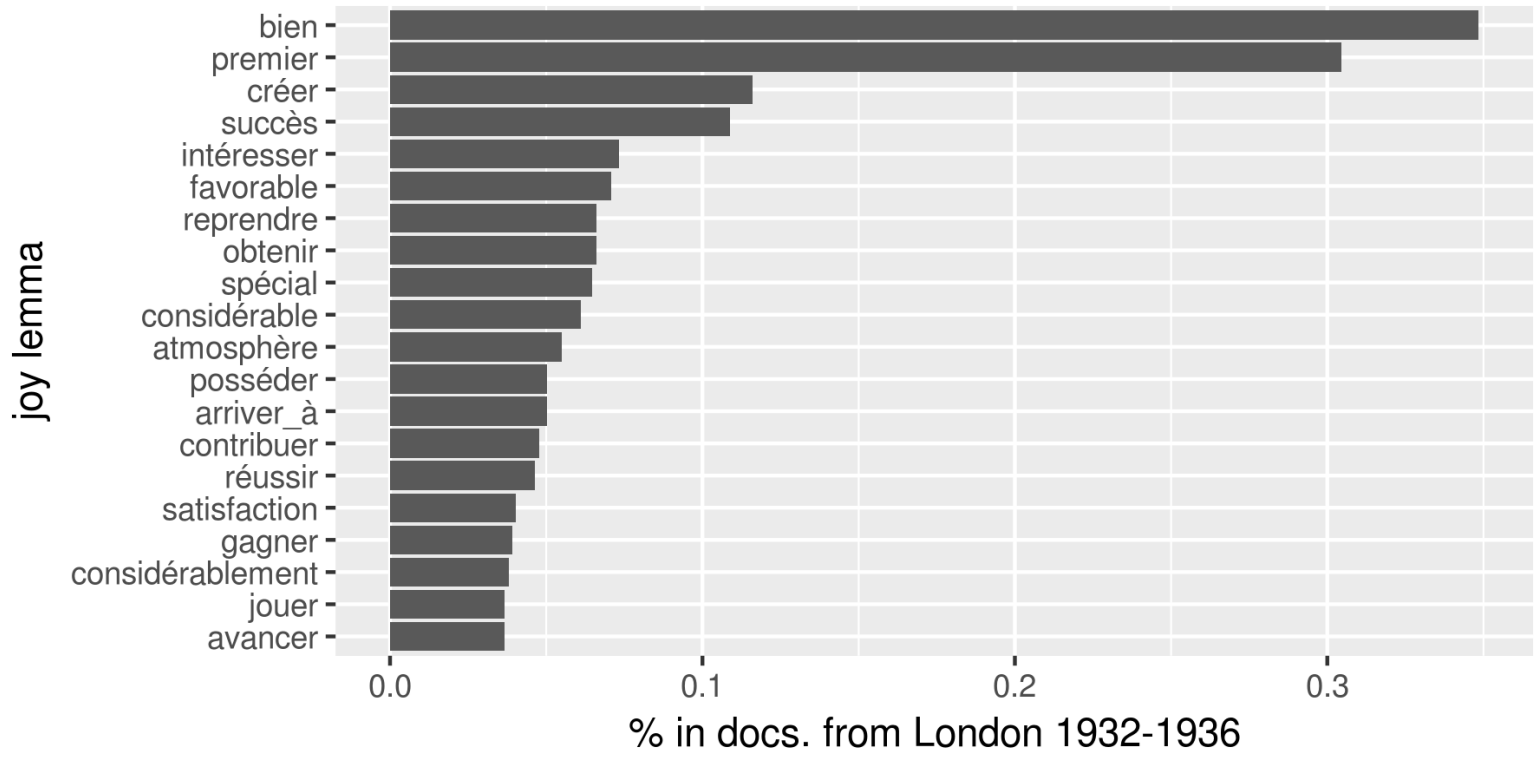

Figure 22: Frequency of lemmas associated with joy in London, 1932-1936. 


\section{Discussion}

In our approach, we have applied a most basic method of sentiment analysis, relying on a precompiled and manually edited sentiment lexicon. Yet, we observe variations in sentiment expression over the course of time, which correlate with historical events. Local specificities can be observed as well.

Sentiment analysis contributed most to our knowledge about sentiments in the administration by identifying the Tokyo reports with strikingly strong sentimental expression over a large set of documents. This identification opens perspective for further focused research on the personal role of the Swiss ambassador in Tokyo for shaping bilateral relations.

In the case of 1930s documents from Stockholm, the method proved itself useful in identifying moments of important social change and giving insight into the interpretation of these events by the Swiss administration.

We can expect emotions expressed by individuals in an administrative apparatus to reflect political or historical events, as much as the other way around. In this respect, it is possible to more closely examine Keller's statement, whereas "the person shaped the activity «. ${ }^{94}$ The analysis of such emotions can contribute to a history of the administration that is not only the history of the rationality of an institutional order, as Max Weber stressed. For a history with diplomatic and administrative practices in its focus, it should be possible then to detect special events, respectively the feelings they evoke against the backdrop of the prevailing mood for each country.

Of course, despite our efforts to eliminate contemporary judgement values, the sentiments observed by our method appear at the interface of $20^{\text {th }}$ century subjects and a $21^{\text {st }}$ century lexicon. Lexiconbased TSA always projects a sentimental ontology of its contemporary context of compilation on past documents. This has not only the obvious risk of an anachronistic interpretation but also the interest of revealing the comparative particularities of the past document's language. In effect, at least since the $19^{\text {th }}$ century hermeneutics, we know that all forms of text interpretation carry a bias induced by the difference between the world from which they are interpreted and the world in which they were composed. In an algorithmic approach, this historical bias is stronger, because fixated in a lexicon, but is also much more explicit. While it is difficult to know what values a historian associates with given expressions during her interpretation, her lexicon reveals exactly what values have been attributed by her interpretation algorithm. This suggests work focused on the construction of placeand time-specific sentiment lexica as a heuristic method in history. The association of lemmas with sentiments in such lexica, considered in its historical dynamic, could give us a framework for specifying semantic shifts and, through these, the evolution of the world of sentiments. We have identified how corpus-based lexicon construction and machine learning methods for word sense induction could offer a methodological solution to do so.

In further work, beyond the benefit of the discovery of significant phases in bilateral diplomatic relations, TSA could also help to detect the fingerprint of authors in aggregated (political) reports that are the base for decisions of the administration and the government. We endeavour to achieve this by a more systematic distinction between the first- and the second-level subject of emotion expression in the sentiment lexicon.

Generally, we believe that TSA offers a powerful instrument for an evidence-based, empirically funded historiography. Bridging distant and close reading in historical science, it contributes to the closure of the old historiographical gap between history focused on individual action and history focused on structural phenomena, by considering historical subjects of emotions on multiple scales and bringing the individual into perspective without losing sight of the aggregate.

Last but not the least, the description and interpretation of administrative practices on a new empirical basis can help to make the administrative history of Switzerland more visible and increase understanding of how the administration works. 


\section{Annex: Top 100 Words per Sentiment}

The following tables give frequencies of the top 100 words for each emotion, ordered by frequency in the corpus. In strikethrough, words that we removed from the original feel dictionary prior to analysis are listed.

Positive, joy, surprise and disgust

\begin{tabular}{|c|c|c|c|c|c|c|c|c|}
\hline & \multicolumn{2}{|c|}{ Positive } & \multicolumn{2}{|c|}{ Joy } & \multicolumn{2}{|c|}{ Surprise } & \multicolumn{2}{|c|}{ Disgust } \\
\hline & Feature & Frequency & Feature & Frequency & Feature & Frequency & Feature & Frequency \\
\hline 1 & gouvernement & 82,146 & Bien & 39,114 & nouveau & 44,621 & pouvoif & 120,136 \\
\hline 2 & pays & 71,717 & premier & 30,291 & prendre & 31,759 & politique & 70,722 \\
\hline 3 & politique & 70,722 & économique & 23,352 & aucun & 25,146 & non & 19,430 \\
\hline 4 & état & 51,399 & partie & $20,88 z$ & problème & 19,672 & seul & 18,545 \\
\hline 5 & ministre & 49,981 & obtenir & 12,580 & travait & 17,529 & étranger & 18,438 \\
\hline 6 & générat & 46,573 & vie & 10,601 & actuel & 16,036 & sujet & 18,063 \\
\hline 7 & grand & 42,568 & reprendre & 9757 & possible & 14,526 & socialiste & 14,747 \\
\hline 8 & président & 42,563 & créer & 9130 & trop & 12,556 & chose & 12,721 \\
\hline 9 & devoif & 42,539 & rappeler & 9038 & présent & 12,162 & intérieur & 71,474 \\
\hline 10 & bien & 39,114 & intéresser & 7873 & occasion & 11,784 & manière & 8305 \\
\hline 11 & monsieur & 37,140 & libre & 7578 & prévoir & 10,211 & mentir & 6798 \\
\hline 12 & donner & 31,156 & date & 6653 & bon & 9315 & opposer & 6520 \\
\hline 13 & jour & 31,087 & spécial & 6466 & particulier & 8405 & gauche & 6438 \\
\hline 14 & premier & 30,291 & succès & 6375 & exposer & 8179 & éviter & 5790 \\
\hline 15 & sou & 29,896 & favorable & 5349 & crise & 7677 & matière & 5662 \\
\hline 16 & situation & 29,196 & jouer & 5119 & liberté & 7647 & ennemi & 5471 \\
\hline 17 & mettre & 28,808 & offrir & 4705 & art & 7386 & mort & 5458 \\
\hline 18 & trouver & 28,551 & réussir & 4574 & malgré & 7185 & congrès & 4882 \\
\hline 19 & part & 27,794 & terminer & 4559 & différent & 6943 & incident & 4834 \\
\hline 20 & allemand & 27,019 & gagner & 4235 & événement & 6724 & économie & 4803 \\
\hline 21 & droit & 26,471 & ergane & 4149 & perdre & 6657 & tâche & 4559 \\
\hline 22 & rapport & 26,430 & enfant & 3908 & indépendance & 6528 & vice & 4266 \\
\hline 23 & peuple & 24,785 & contribuer & 3858 & circonstance & 5892 & tour & 4253 \\
\hline 24 & affaire & 24,605 & considérable & 3820 & voyage & 5886 & mauvais & 4189 \\
\hline 25 & national & 24,467 & faciliter & 3647 & second & 5806 & accuser & 4134 \\
\hline 26 & savoir & 24,337 & maintien & 3464 & arrêter & 5726 & tribunat & 4129 \\
\hline 27 & économique & 23,352 & existence & 3430 & charge & 5689 & étendre & 4113 \\
\hline 28 & année & 23,226 & satisfaction & 3428 & apprendre & 5171 & adversaire & 3940 \\
\hline 29 & temps & 22,814 & posséder & 3357 & incident & 4834 & modifier & 3720 \\
\hline 30 & mesure & 22,341 & heureux & 3309 & pacifique & 4795 & compromettre & 3630 \\
\hline 31 & nation & $z 2,10 z$ & accueillir & 3154 & espoir & 4702 & abandonner & 3591 \\
\hline 32 & Heu & 21,594 & naître & 3100 & appel & 4656 & vif & 3559 \\
\hline
\end{tabular}




\begin{tabular}{|c|c|c|c|c|c|c|c|c|}
\hline & \multicolumn{2}{|c|}{ Positive } & \multicolumn{2}{|l|}{ Joy } & \multicolumn{2}{|c|}{ Surprise } & \multicolumn{2}{|c|}{ Disgust } \\
\hline & Feature & Frequency & Feature & Frequency & Feature & Frequency & Feature & Frequency \\
\hline 33 & public & 21,293 & aboutir & 2760 & quitter & 4639 & topie & 3403 \\
\hline 34 & moment & 21,143 & satisfaire & 2655 & vote & 4627 & posséder & 3357 \\
\hline 35 & partie & $z 0,88 z$ & profit & 2546 & voter & 4468 & air & 3285 \\
\hline 36 & membre & 20,871 & avancer & 2438 & tirer & 4348 & noir & 3250 \\
\hline 37 & effet & 19,515 & atmosphère & 2240 & jeune & 4334 & ignorer & 3090 \\
\hline 38 & foi & 19,385 & bénéfice & 2211 & tour & 4253 & anti & 3067 \\
\hline 39 & tenir & 19,125 & libérer & 2116 & parer & 4081 & parvenir & 3031 \\
\hline 40 & rendre & 19,021 & énergie & 1951 & terrain & 3969 & dépasser & 2938 \\
\hline 41 & sembler & 18,886 & bonnes & 1924 & immédiatement & 3950 & évident & 2829 \\
\hline 42 & article & 18,850 & arriver_à & 1909 & avance & 3940 & tarif & 2824 \\
\hline 43 & intérêt & 18,316 & santé & 1894 & expérience & 3924 & exclure & 2728 \\
\hline 44 & croire & 18,236 & pro & 1865 & siège & 3891 & échec & 2676 \\
\hline 45 & paix & 18,115 & majesté & 1607 & surprendre & 3862 & menacer & 2654 \\
\hline 46 & ambassadeur & 17,546 & remercier & 1606 & agression & 3719 & blesser & 2584 \\
\hline 47 & travail & 17,529 & facilement & 1575 & saisir & 3660 & faute & 2574 \\
\hline 48 & international & 17,480 & bénéficier & 1502 & grave & 3612 & modification & 2518 \\
\hline 49 & eonférence & 17,280 & songer & 1462 & vif & 3559 & prisonnier & 2516 \\
\hline 50 & permettre & 17,009 & accomplir & 1455 & inviter & 3510 & moindre & 2469 \\
\hline 51 & accord & 16,706 & saluer & 1449 & conservateur & 3493 & socialisme & 2378 \\
\hline 52 & traiter & 16,625 & théâtre & 1350 & immédiat & 3459 & suffisant & 2368 \\
\hline 53 & agir & 16,531 & prospérité & 1328 & tenter & 3375 & séparer & 2339 \\
\hline 54 & faison & 16,433 & vaincre & 1313 & souhaiter & 3358 & violent & 2334 \\
\hline 55 & relation & 16,387 & féliciter & 1247 & inspirer & 3251 & souffrir & 2331 \\
\hline 56 & république & 16,367 & opportun & 1233 & rencontrer & 3153 & faible & 2328 \\
\hline 57 & moyen & 16,149 & concert & 1197 & attribuer & 3108 & finalement & 2216 \\
\hline 58 & million & 15,794 & fille & 1179 & chance & 3067 & sacrifice & 2206 \\
\hline 59 & conseil & 15,726 & rétablissement & 1158 & secret & 3055 & écarter & 2174 \\
\hline 60 & commission & 15,714 & vacance & 1144 & attaquer & 2923 & éprouver & 2160 \\
\hline 61 & eompte & 15,634 & joie & 1136 & dangereux & 2788 & hostile & 2154 \\
\hline 62 & monde & 15,620 & énergique & 1120 & argent & 2773 & nul & 2115 \\
\hline 63 & fort & 15,416 & interpréter & 1079 & pousser & 2747 & dépit & 2108 \\
\hline 64 & déelarer & 14,988 & précieux & 1052 & rencontre & 2720 & foule & 2081 \\
\hline 65 & opinion & 14,964 & considérablement & 1046 & extraordinaire & 2706 & FAUX & 2054 \\
\hline 66 & produire & 14,951 & remarquable & 1027 & allusion & 2704 & offensif & 2006 \\
\hline 67 & union & 14,936 & bien_être & 960 & exception & 2681 & rejeter & 2005 \\
\hline 68 & suive & 74,893 & triomphe & 928 & rapide & 2639 & dur & 1985 \\
\hline 69 & socialiste & 14,741 & animer & 913 & attirer & 2509 & hostilité & 1929 \\
\hline 70 & parler & 14,658 & bis & 906 & trouble & 2385 & con & 1856 \\
\hline 71 & toi & 74,597 & disponible & 871 & violent & 2334 & sanction & 1856 \\
\hline 72 & entendre & 14,595 & heureusement & 863 & unique & 2324 & charbon & 1850 \\
\hline 73 & possible & 14,526 & congé & 845 & aborder & 2278 & pli & 4843 \\
\hline 74 & également & 14,064 & rassurer & 842 & monnaie & 2218 & reproche & 1802 \\
\hline
\end{tabular}




\begin{tabular}{|c|c|c|c|c|c|c|c|c|}
\hline & \multicolumn{2}{|c|}{ Positive } & \multicolumn{2}{|c|}{ Joy } & \multicolumn{2}{|c|}{ Surprise } & \multicolumn{2}{|c|}{ Disgust } \\
\hline & Feature & Frequency & Feature & Frequency & Feature & Frequency & Feature & Frequency \\
\hline 75 & personne & 14,056 & songe & 821 & finalement & 2216 & prétexte & 1785 \\
\hline 76 & service & 13,908 & paye & 798 & démission & 2144 & accusation & 1778 \\
\hline 77 & comprendre & 13,779 & doter & 795 & historique & 2107 & possession & 1727 \\
\hline 78 & nombre & 13,616 & le_meilleur & 790 & frapper & 2094 & sensible & 1694 \\
\hline 79 & recevoir & 13,612 & célébrer & 773 & organisme & 2088 & prolonger & 1588 \\
\hline 80 & puissance & 13,573 & inaugurer & 748 & foule & 2081 & dictature & 1568 \\
\hline 81 & déclaration & 13,560 & triompher & 725 & encourager & 2054 & reprocher & 1549 \\
\hline 82 & ordre & 13,474 & sourire & 702 & obstacle & 2045 & tort & 1501 \\
\hline 83 & penser & 13,470 & content & 679 & tourner & 1987 & sang & 1489 \\
\hline 84 & connaître & 13,268 & salon & 676 & jeunesse & 1923 & suppression & 1421 \\
\hline 85 & assurer & 13,026 & bonheur & 673 & cacher & 1872 & sol & 1417 \\
\hline 86 & organisation & 12,929 & courtoisie & 646 & prier & 1866 & retard & 1410 \\
\hline 87 & journat & 12,811 & aisé & 626 & bombe & 1817 & riche & 1398 \\
\hline 88 & action & 12,795 & avantageux & 620 & secours & 1803 & détenir & 1377 \\
\hline 89 & lettre & 12,752 & amnistie & 594 & franc & 1783 & rumeur & 1366 \\
\hline 90 & représentant & 12,671 & vigueur & 591 & rupture & 1776 & taire & 1339 \\
\hline 91 & suite & 72,586 & éclat & 579 & chute & 1742 & dénoncer & 1330 \\
\hline 92 & obtenir & 12,580 & visiteur & 579 & peur & 1733 & maladie & 1310 \\
\hline 93 & surtout & 12,579 & victorieux & 569 & constant & 1684 & négatif & 1275 \\
\hline 94 & chine & 12,362 & repos & 567 & urgence & 1620 & criminel & 1242 \\
\hline 95 & présent & 12,162 & combler & 561 & compléter & 1597 & dommage & 1240 \\
\hline 96 & aller & 12,073 & accéder & 556 & éclater & 1594 & mécontentement & 1235 \\
\hline 97 & position & 11,918 & fleur & 554 & sincère & 1558 & malheureux & 1223 \\
\hline 98 & occasion & 11,784 & repartir & 554 & enthousiasme & 1556 & repousser & 1223 \\
\hline 99 & assembler & 11,749 & bienvenu & 551 & vague & 1547 & haine & 1220 \\
\hline 100 & discours & 11,702 & jardin & 537 & surgif & 1478 & avocat & 1210 \\
\hline
\end{tabular}

\section{Negative, fear, sadness and anger}

\begin{tabular}{|c|c|c|c|c|c|c|c|c|}
\hline & \multicolumn{2}{|c|}{ Negative } & \multicolumn{2}{|c|}{ Fear } & \multicolumn{2}{|c|}{ Sadness } & \multicolumn{2}{|c|}{ Anger } \\
\hline & Feature & Frequency & Feature & Frequency & Feature & Frequency & Feature & Frequency \\
\hline 1 & pouvoir & 120,136 & gouvernement & 82,146 & dernier & 38,322 & politique & 70,722 \\
\hline 2 & contre & 41,728 & dernier & 38,322 & veuloif & 34,420 & contre & 41,728 \\
\hline 3 & dernier & 38,322 & vouloir & 34,420 & guerre & 32,865 & guerre & 32,865 \\
\hline 4 & vouloir & 34,420 & guerre & 32,865 & aucun & 25,146 & militaire & 24,566 \\
\hline 5 & guerre & 32,865 & prendre & 31,759 & problème & 19,672 & eommuniste & 23,137 \\
\hline 6 & moins & 25,810 & militaire & 24,566 & seul & 18,545 & armer & 21,962 \\
\hline 7 & aucun & 25,146 & communiste & 23,137 & étranger & 18,438 & problème & 19,672 \\
\hline 8 & militaire & 24,566 & armer & 21,962 & sujet & 18,063 & seul & 18,545 \\
\hline 9 & eommuniste & 23,137 & problème & 19,672 & faillir & 15,922 & sujet & 18,063 \\
\hline 10 & armer & 21,962 & seul & 18,545 & socialiste & 14,741 & demander & 15,681 \\
\hline 11 & problème & 19,672 & étranger & 78,438 & rien & 14,031 & socialiste & 74,744 \\
\hline
\end{tabular}




\begin{tabular}{|c|c|c|c|c|c|c|c|c|}
\hline & \multicolumn{2}{|c|}{ Negative } & \multicolumn{2}{|c|}{ Fear } & \multicolumn{2}{|c|}{ Sadness } & \multicolumn{2}{|c|}{ Anger } \\
\hline & Feature & Frequency & Feature & Frequency & Feature & Frequency & Feature & Frequency \\
\hline 12 & non & 19,430 & déclarer & 14,988 & peu & 13,683 & chose & 12,721 \\
\hline 13 & seul & 18,545 & condition & 14,803 & fin & 12,100 & régime & 12,562 \\
\hline 14 & étranger & 18,438 & socialiste & 74,747 & laisser & 11,581 & troupe & 11,277 \\
\hline 15 & sujet & 18,063 & chose & 12,721 & porter & 11,379 & défense & 9741 \\
\hline 16 & faillir & 15,922 & régime & 12,562 & petit & 11,008 & ligne & 9486 \\
\hline 17 & demander & 75,681 & trop & 12,556 & charger & 10,391 & lutte & 9002 \\
\hline 18 & rien & 14,031 & fin & 12,100 & eoncerner & 10,001 & opposition & 8943 \\
\hline 19 & peu & 13,683 & troupe & 11,277 & lutte & 9002 & manière & 8305 \\
\hline 20 & ancien & 13,107 & charger & 10,391 & occuper & 8154 & occuper & 8154 \\
\hline 21 & suivant & 12,950 & eoncerner & 10,001 & difficulté & 7941 & poursuivre & 7909 \\
\hline 22 & chose & 12,721 & défense & 9741 & poursuivre & 7909 & vis & 7830 \\
\hline 23 & régime & 12,562 & lutte & 9002 & crise & 7677 & crise & 7677 \\
\hline 24 & trop & 12,556 & particulier & 8405 & art & 7386 & conflit & 7545 \\
\hline 25 & attendre & 12,530 & exposer & 8179 & difficile & 7327 & coup & 7373 \\
\hline 26 & fin & 12,100 & poursuivre & 7909 & contraire & 7143 & contraire & 7143 \\
\hline 27 & laisser & 11,581 & crise & 7677 & mentir & 6798 & soumettre & 7108 \\
\hline 28 & troupe & 11,277 & coup & 7373 & perdre & 6657 & armes & 7036 \\
\hline 29 & petit & 11,008 & craindre & 7364 & opposer & 6520 & mentir & 6798 \\
\hline 30 & charger & 10,391 & contraire & 7143 & nécessiter & 5826 & provoquer & 6630 \\
\hline 31 & eoncerner & 10,001 & montrer & 7066 & estime & 5582 & opposer & 6520 \\
\hline 32 & lutte & 9002 & armes & 7036 & ennemi & 5471 & eampagne & 6432 \\
\hline 33 & opposition & 8943 & différent & 6943 & mort & 5458 & imposer & 6226 \\
\hline 34 & manière & 8305 & perdre & 6657 & tendance & 5200 & charge & 5689 \\
\hline 35 & exposer & 8179 & opposer & 6520 & mal & 5064 & matière & 5662 \\
\hline 36 & occuper & 8154 & gauche & 6438 & obligation & 5014 & ennemi & 5471 \\
\hline 37 & besoin & 8089 & eampagne & 6432 & division & 4967 & menace & 5190 \\
\hline 38 & extérieur & 8051 & imposer & 6226 & danger & 4928 & propagande & 5001 \\
\hline 39 & difficulté & 7941 & voyage & 5886 & incident & 4834 & division & 4967 \\
\hline 40 & poursuivre & 7909 & éviter & 5790 & sérieux & 4825 & sérieux & 4825 \\
\hline 41 & crise & 7677 & confiance & 5729 & soldat & 4789 & soldat & 4789 \\
\hline 42 & conflit & 7545 & arrêter & 5726 & prétendre & 4704 & prétendre & 4704 \\
\hline 43 & total & 7478 & charge & 5689 & quitter & 4639 & appel & 4656 \\
\hline 44 & coup & 7373 & empêcher & 5623 & vote & 4627 & quitter & 4639 \\
\hline 45 & craindre & 7364 & ennemi & 5471 & tâche & 4559 & vote & 4627 \\
\hline 46 & difficile & 7327 & police & 5394 & manquer & 4521 & extrême & 4598 \\
\hline 47 & note & 7265 & opération & 5337 & voter & 4468 & voter & 4468 \\
\hline 48 & malgré & 7185 & menace & 5190 & estimer & 4415 & défendre & 4389 \\
\hline 49 & contraire & 7143 & dépense & 5087 & peine & 4382 & exiger & 4377 \\
\hline 50 & soumettre & 7108 & obligation & 5014 & doute & 4376 & tirer & 4348 \\
\hline 51 & armes & 7036 & propagande & 5001 & tirer & 4348 & impôt & 4275 \\
\hline 52 & mentir & 6798 & danger & 4928 & impôt & 4275 & vice & 4266 \\
\hline 53 & servir & 6794 & obliger & 4886 & somme & 4261 & tour & 4253 \\
\hline
\end{tabular}




\begin{tabular}{|c|c|c|c|c|c|c|c|c|}
\hline & \multicolumn{2}{|c|}{ Negative } & \multicolumn{2}{|c|}{ Fear } & \multicolumn{2}{|c|}{ Sadness } & \multicolumn{2}{|c|}{ Anger } \\
\hline & Feature & Frequency & Feature & Frequency & Feature & Frequency & Feature & Frequency \\
\hline 54 & perdre & 6657 & incident & 4834 & revenu & 4254 & exécution & 4244 \\
\hline 55 & provoquer & 6630 & sérieux & 4825 & exécution & 4244 & mauvais & 4189 \\
\hline 56 & refuser & 6612 & soldat & 4789 & mauvais & 4189 & histoire & 4162 \\
\hline 57 & opposer & 6520 & prétendre & 4704 & histoire & 4162 & accuser & 4134 \\
\hline 58 & gauche & 6438 & appel & 4656 & accuser & 4134 & tribunat & 4129 \\
\hline 59 & imposer & 6226 & quitter & 4639 & étendre & 4113 & colonie & 4127 \\
\hline 60 & bien_que & 6135 & extrême & 4598 & impossible & 4109 & étendre & 4113 \\
\hline 61 & éviter & 5790 & tâche & 4559 & pression & 4022 & pression & 4022 \\
\hline 62 & arrêter & 5726 & maréchal & 4545 & terrain & 3969 & conseiller & 4013 \\
\hline 63 & charge & 5689 & manquer & 4521 & radical & 3968 & revanche & 4000 \\
\hline 64 & matière & 5662 & marchandise & 4425 & siège & 3891 & terrain & 3969 \\
\hline 65 & empêcher & 5623 & doute & 4376 & dette & 3851 & adversaire & 3940 \\
\hline 66 & ennemi & 5471 & tirer & 4348 & subir & 3730 & siège & 3891 \\
\hline 67 & mort & 5458 & exécution & 4244 & modifier & 3720 & renforcer & 3779 \\
\hline 68 & période & 5347 & mauvais & 4189 & occupation & 3677 & agression & 3719 \\
\hline 69 & opération & 5337 & masse & 4156 & revenif & 3639 & saisir & 3660 \\
\hline 70 & menace & 5190 & accuser & 4134 & compromettre & 3630 & abandonner & 3591 \\
\hline 71 & dépense & 5087 & tribunat & 4129 & grave & 3612 & moral & 3467 \\
\hline 72 & mal & 5064 & colonie & 4127 & abandonner & 3591 & eommunisme & 3412 \\
\hline 73 & obligation & 5014 & étendre & 4113 & eommunisme & 3412 & copie & 3403 \\
\hline 74 & propagande & 5001 & pression & 4022 & noir & 3250 & posséder & 3357 \\
\hline 75 & division & 4967 & conseiller & 4013 & oublier & 3222 & participation & 3321 \\
\hline 76 & danger & 4928 & assurance & 3970 & retirer & 3220 & noir & 3250 \\
\hline 77 & juger & 4907 & terrain & 3969 & causer & 3108 & insister & 3208 \\
\hline 78 & obliger & 4886 & avance & 3940 & ignorer & 3090 & grève & 3109 \\
\hline 79 & incident & 4834 & adversaire & 3940 & condamner & 3085 & anti & 3067 \\
\hline 80 & soldat & 4789 & risque & 3938 & limiter & 3053 & limiter & 3053 \\
\hline 81 & alors_que & 4755 & siège & 3891 & perte & 3033 & pierre & 3049 \\
\hline 82 & prétendre & 4704 & surprendre & 3862 & tomber & 3025 & perte & 3033 \\
\hline 83 & appel & 4656 & agression & 3719 & neutre & 3019 & armement & 2996 \\
\hline 84 & quitter & 4639 & occupation & 3677 & dépasser & 2938 & attaquer & 2923 \\
\hline 85 & extrême & 4598 & saisir & 3660 & diminuer & 2886 & atomique & 2889 \\
\hline 86 & tâche & 4559 & grave & 3612 & se_rendre & 2855 & évident & 2829 \\
\hline 87 & manquer & 4521 & abandonner & 3591 & tarif & 2824 & tarif & 2824 \\
\hline 88 & tonne & 4483 & vif & 3559 & dangereux & 2788 & rang & 2792 \\
\hline 89 & peine & 4382 & sort & 3534 & terme & 2786 & dangereux & 2788 \\
\hline 90 & exiger & 4377 & communisme & 3412 & exclure & 2728 & argent & 2773 \\
\hline 91 & doute & 4376 & posséder & 3357 & laisse & 2677 & exclure & 2728 \\
\hline 92 & impôt & 4275 & changer & 3295 & échec & 2676 & allusion & 2704 \\
\hline 93 & vice & 4266 & noir & 3250 & blesser & 2584 & laisse & 2677 \\
\hline 94 & somme & 4261 & oublier & 3222 & faute & 2574 & résistance & 2661 \\
\hline 95 & exécution & 4244 & condamner & 3085 & nuit & 2540 & menacer & 2654 \\
\hline
\end{tabular}




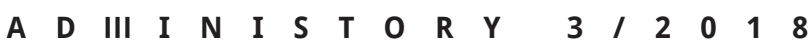

\begin{tabular}{|c|c|c|c|c|c|c|c|c|}
\hline & \multicolumn{2}{|c|}{ Negative } & \multicolumn{2}{c|}{ Fear } & \multicolumn{2}{c|}{ Sadness } & \multicolumn{2}{c|}{ Anger } \\
\hline & Feature & Frequency & Feature & Frequency & Feature & Frequency & Feature & Frequency \\
\hline 96 & mauvais & 4189 & secret & 3055 & interdire & 2531 & jeter & 2628 \\
\hline 97 & histoire & 4162 & perte & 3033 & modification & 2518 & blesser & 2584 \\
\hline 98 & masse & 4156 & tomber & 3025 & combat & 2517 & interdire & 2531 \\
\hline 99 & accuser & 4134 & neutre & 3019 & prisonnier & 2516 & combat & 2517 \\
\hline 100 & colonie & 4127 & armement & 2996 & recette & 2508 & prisonnier & 2516 \\
\hline
\end{tabular}


1 In this sense, we concur with the concept of sgroup-level emotion examined by Mercer, see Jonathan Mercer: „Feeling like a State: social emotion and identity“, in: International Theory 6/3 (2014), pp. 515-535, online at: https://doi.org/10.1017/S1752971914000244 (1. 8. 2018), though our analysis has a different object and takes another theoretical path.

2 Gao, Goetz, Mazumder and Connelly have shown that a topic modelling approach can identify 30 most significant international events during the 1973 and 1977 by analysing to 1.9 million declassified cables and the metadata associated with 0.4 million diplomatic documents of US State Department records (US National Archives). Our approach, based on a significantly smaller corpus, examines the usability of sentiment analysis for similar historical event detection, see Yuanjun Gao et al.: Mining Events with Declassified Diplomatic Documents, Cornell 2017, online at: https:// arxiv.org/abs/1712.07319 (1. 8. 2018).

3 Twitter, @realDonaldTrump, 14:31 - 18. 11. 2017, online at: https:// twitter.com/realDonaldTrump/status/931877599034388480 (1. 8. 2018).

4 Twitter, @BorisJohnson, 16:44 - 3. 11. 2017, online at: https://twitter. com/BorisJohnson/status/926475222609547266 (20. 9. 2018.)

5 See e. g. Andranik Tumasjan u. a.: Predicting elections with twitter. What 140 characters reveal about political sentiment, in: Proceedings of the Fourth International AAAI Conference on Weblogs and Social Media (2010), pp. 178-185.

6 SFA, fond E2300* Eidgenössisches politisches Departement: Politische und militärische Berichte der Auslandvertretungen (1848-1965) 1848-1965. For later periods see the fonds E230001* and E2010-02A*: Eidgenössisches politisches Departement: Politische und militärische Berichte der Auslandvertretungen (1966-1978) 1966-1978 and (1979-) 1979-1990.

7 Carlos S. F. Jagmetti: Alte Schatten, neue Schatten. Zeitzeuge in den USA, 1995-1997, Zürich 2002.

8 Herren and Zala wrote about the figure of the expert in Swiss foreign policy. They concentrated on the international conferences: Madleine Herren / Sacha Zala: «Die Experten verpflichten ihre Regierungen in keiner Weise،. Experten im Milizsystem der schweizerischen Aussenpolitik der Zwischenkriegszeit«, in: Traverse 2001/1, pp. 96-109.

9 Pietro Gerbore: Formen und Stile der Diplomatie, Reinbek 1964, p. 65.

10 Gerbore: Formen und Stile der Diplomatie, p 87.

11 For Switzerland, see Guido Koller et al.: Helvetia hält Hof Staatsbesuche in der Schweiz, Bern 2002.

12 Gerbore: Formen und Stile der Diplomatie, pp. 134-200.

13 Gerbore: Formen und Stile der Diplomatie, p. 43.

14 Claude Altermatt: "Konsularwesen«, in: Historisches Lexikon der Schweiz, online at: http://www.hls-dhs-dss.ch/textes/d/D13809.php (1. 8. 2018).

15 Claude Altermatt: Les débuts de la diplomatie professionnelle en Suisse (1848-1914), Fribourg 1990, p. 107.

16 Altermatt: Les débuts, p. 159.

17 Claude Altermatt: Zwei Jahrhunderte Schweizer Aussenvertretungen 1798-1998 - Deux siècles de représentations extérieures de la Suisse 1798-1998, Bern 1998. For a history of the Swiss diplomacy, also see: Albert Redard: Die diplomatischen Vertretungen, Dissertation, Universität Bern 1948; Franz A. Blankart / Jaçues Freymond / Nadine Galvani: La Suisse et la diplomatie multilatérale, Genf 1978; Paul Widmer: Diplomatie. ein Handbuch, Zürich 22018.

18 Diplomatischer Concours und Ausbildung, online at: https://www. eda.admin.ch/eda/de/home/das-eda/arbeiten-eda/berufserfahrene/ diplomatische_laufbahn/der-diplomatischeberuf.html (1. 8. 2018).
19 https://www.eda.admin.ch/eda/fr/dfae/dfae/travailler-dfae/ berufserfahrene/diplomatische_laufbahn.html (20. 9. 2018).

20 Florian Keller: Botschafterporträts - Schweizer Botschafter in den Zentren der »Macht« zwischen 1945 und 1975, Zürich 2017, p. 50.

21 Keller: Botschafterporträts, p. 348.

22 Keller: Botschafterporträts, p. 352. For further portraits of Swiss diplomats, see Paul Widmer: NZZ Libro, Zürich 2014.

23 According to a rough automatic detection during the scanning part of the process. Some texts detected as French at this point turned out to consist of less than $70 \%$ of French words at a later stage.

24 These metadata were not always reliable. Some of the reports identified as French turned out being written in several languages or containing meaningless sequences of characters.

25 In the tokenization process, we have also removed numbers, punctuation, symbols and French stopwords.

26 The identification of French words was based on the Lexique des Formes Fléchies du Français (LeFFF). Cf. Benoît Sagot: "The Lefff, a freely available and large-coverage morphological and syntactic lexicon for French«, Presented at the 7th International Conference on Language Resources and Evaluation, LREC (2010), online at: https://hal.inria.fr/inria-00521242/document (1. 8. 2018). The $70 \%$ threshold allowed us to eliminate texts mixing languages, while leaving some lenience for texts with misspelled but identifiable French words that LeFFF identified as non-French.

27 Excluding stopwords, numbers and punctuation.

28 There was no Swiss envoy in the USSR between 1923 and 1956, see Peter Collmer: »Russie« (27. 1. 2016), online at: http://www.hls-dhsdss.ch/textes/f/F3376.php (1. 9. 2018).

29 These documents are in another fonds, not yet digitised.

30 Waldo. R. Tobler: »A Computer Movie Simulating Urban Growth in the Detroit Region«, in: Economic Geography 46 (1970), p. 234-240, hier p. 236, online at: https://doi.org/10.2307/143141 (1. 8. 2018).

31 André Ourednik: L'habitant et la cohabitation dans les modèles de I'espace habité, Dissertation, Universität Lausanne 2010, p. 105

32 John Whelchel / Christiane Fellbaum: "Sentiment Analysis of Foreign Documents to Detect Translation Bias. Misconstrued Communications in the European Parliament«, Independent Work Report Spring 2014, online at: http://www.johnwhelchel.com/static/ mysite/index/IWBiases.pdf (1. 8. 2018).

33 The complexity of this psychological disputatio ramifies in neuroscience, biology, linguistics, anthropology and philosophy. Darwin proposed the existence of transcultural basic emotions in an ethically motivated publication, see Charles Darwin: The expression of the emotions in man and animals, London 1872, online at: http://archive.org/details/expressionofemot1872darw (1. 8. 2018). For further discussion, see Keith Oatley / Philip N. Johnson-Laird: »Towards a cognitive theory of emotions«, in: Cognition \& Emotion 1 (1987), pp. 29-50; Andrew Ortony / Terence J. Turner: "What's basic about basic emotions?«, in: Psychological Review 97/3 (1990), pp. 315-331; Paul Ekman, "An Argument for Basic Emotions«, in: Cognition and Emotion 6 (1992), pp. 169-200; Kristen A. Lindquist et al.: »Language and the perception of emotion«, in: Emotion 6/1 (2006), pp. 125-138, online at: https://doi.org/10.1037/1528-3542.6.1.125 (1. 8. 2018); Maria Gendron et al.: »Emotion words shape emotion percepts«, in: Emotion, 12/2 (2012), pp. 314-325, online at: https:// doi.org/10.1037/a0026007 (1. 8. 2018); Paul Ekman / Dacher Keltner: "Darwin's Claim of Universals in Facial Expression Not Challenged «, 27. 3. 2014, online at: https://www.paulekman.com/uncategorized/ darwins-claim-universals-facial-expression-challenged (1. 8. 2018).

34 The term feeling, for instance, has «multiple psychological and physiological definitions ranging from the subjectively accessible 
component of emotions to somatosensory experiences, ideas, and beliefs", see Lauri Nummenmaa et al.: "Maps of subjective feelings«, in: Proceedings of the National Academy of Sciences, online at: https://doi.org/10.5281/zenodo.1291730 (28. 8. 2018). Etymologically speaking, the entire vocabulary of emotions evolves around the idea of movement and effect, as suggested by the Latin ex-movere (to move out), ad-facere (to be acted upon) and the old English felan (to touch). Sentiment re-enters into modern English from 17th c. French, where it denotes a faculty to receive physical impressions. Depending on the choice of the term, focus is given to the environment moving a subject or to the subject moving the environment by the expression of his or her emotion. "It is generally agreed that emotions are something people experience and something they do. We have emotions and we manifest emotions. Much of the difficulty in defining them has come from the traditional view that these are two essentially different activities". See Monique Scheer: »Are Emotions a Kind of Practice (and Is That What Makes Them Have a History)? A Bourdieuian Approach to Understanding Emotion«, in: History and Theory 51/2 (2012), pp. 193-220, online at: https://doi.org/10.1111/j.1468-2303.2012.00621.x (1. 8. 2018). In effect, some authors seek to normalise differences between these terms for the practical purposes of their own research, which diverge from ours.

35 Jan Plamper: Geschichte und Gefühl. Grundlagen der Emotionsgeschichte, München 2012.

36 Scheer: "Are Emotions a Kind of Practice«.

37 Oatley /Johnson-Laird: "Towards a cognitive theory of emotions«.

38 Max Weber: Wirtschaft und Gesellschaft, Tübingen ${ }^{5} 1976$, online at: https://www.textlog.de/weber_wirtschaft.html (1. 8. 2018).

39 Further examples: [rage/terror, anxiety, joy] Jeffrey A. Gray / Neil McNaughton: The neuropsychology of anxiety. An enquiry into the function of the septo-hippocampal system, Oxford 1982; ders.: "The whole and its parts. Behaviour, the brain, cognition and emotion «, in: Bulletin of the British Psychological Society 38 (1985), pp. 99-112; [anger, interest, contempt, disgust, distress, fear, joy, shame, surprise] Silvan S. Tomkins: "Affect theory», in: Klaus R. Scherer / Paul Ekman (eds.): Approaches to emotion, Hillsdale 1984, pp. 163-195; [expectancy, fear, rage, panic] Jaak Panksepp: Affective neuroscience. The foundations of human and animal emotions, Oxford 1998 (2004); [anger, disgust, anxiety, happiness, sadness] Oatley / Johnson-Laird: "Towards a cognitive theory of emotions«; [anger, contempt, disgust, distress, fear, guilt, interest, joy, shame, surprise] Caroll E. Izard: Human emotions, New York 1977. Note that sentiment analysis is not necessarily based on text. Its development is rather tributary to studies of facial expressions, see Paul Ekman / Wallace V. Friesen: "The repertoire of nonverbal behaviour. Categories, origins, usage, and coding «, in: Semiotica 1 (1969), pp. 49-98; idem: „Universals and Cultural Differences in Facial Expression of Emotion«, in: James K. Cole (ed.): Nebraska Symposium on Motivation, 1971, Lincoln 1972, pp. 207-283; Izard: Human emotions; Paul Ekman / Wallace V. Friesen / Phoebe Ellsworth: "What emotion categories or dimensions can observers judge from facial behavior?«, in: Paul Ekman (ed.): Emotion in the human face, New York 1982, pp. 39-55; Rachel E. Jack / Oliver G. B. Garrod / Philippe G. Schyns: "Dynamic facial expressions of emotion transmit an evolving hierarchy of signals over time«, in: Current Biology 24/2 (2014), pp. 187-192, online at: https://doi. org/10.1016/j.cub.2013.11.064 (1. 8. 2018), brain activity, see Gray / McNaughton: The neuropsychology of anxiety; idem: "The whole and its parts; Tomkins: "Affect theory«; Jaak Panksepp: »Toward a general psychobiological theory of emotions«, in: The Behavioral and Brain Sciences 5 (1982), pp. 407-467; Panksepp: Affective neuroscience; or neuroendocrinology, see Panksepp: „Toward a general psychobiological theory of emotions«; Panksepp: Affective neuroscience; Judith A Toronchuk / George F.R. Ellis: „Affective Neuronal Selection. The Nature of the Primordial Emotion Systems", in: Frontiers in Psychology 3 (2012): p. 589, online at: https://www. frontiersin.org/articles/10.3389/fpsyg.2012.00589/full (1. 8. 2018).

40 Ekman: "Universals and Cultural Differences«; Ekman / Friesen / Ellsworth: »What emotion categories«.

41 Robert Plutchik: The emotions. Facts, theories, and a new model, New York 1962, online at: http://archive.org/details/ emotionsfactsthe00plut (1. 8. 2018); idem: »A general psychoevolutionary theory of emotion «, in: Ders. / Henry Kellerman (eds.): Emotion. Theory, research, and experience 1, Theories of emotion, New York 1980, pp. 3-33.

42 Jack / Garrod / Schyns: "Dynamic facial expressions«. The authors explicitly argue for the reduction of Ekman emotions by combining fear / surprise and anger / disgust.

43 Phillip Shaver et al: „Emotion knowledge. Further exploration of a prototype approach«, in: Journal of Personality and Social Psychology 52/6 (1987), pp. 1061-1086.

44 Bo Pang / Lillian Lee: „Opinion Mining and Sentiment Analysis«, in: Information Retrieval 2/1-2 (2008), pp. 1-135.

45 Vauth Hatzivassiloglou / Kathleen McKeown: „Predicting the semantic orientation of adjectives", in: Proceedings of the Eighth Conference on European Chapter of the Association for Computational Linguistics 35 (1997), pp. 174-181.

46 Erik Cambria et al.: "SenticNet 4. A Semantic Resource for Sentiment Analysis Based on Conceptual Primitives«, in: Proceedings of COLING 2016, the 26th International Conference on Computational Linguistics (2016), pp. 2666-2677, online at: http://sentic.net/ senticnet-4.pdf (1. 8. 2018).

47 Saif M. Mohammad / Peter D Turney: „Crowdsourcing a Word-Emotion Association Lexicon«, in: Computational Intelligence 29/3 (2013), pp. 436-465, online at: http://arxiv.org/abs/1308.6297 (1. 8. 2018).

48 Andreas Blank/Peter Koch:HistoricalSemanticsand Cognition, Berlin, Boston 22013, online at: https://doi.org/10.1515/9783110804195 (1. 8. 2018)

49 William L. Hamilton, Jure Leskovec, Dan Jurafsky: "Diachronic Word Embeddings Reveal Statistical Laws of Semantic Change«, in: ArXiv:1605.09096 [CS] (2016), online at: http://arxiv.org/ abs/1605.09096 (1. 8. 2018)

50 CH-BAR\#E2300\#1000-716\#1013\#2\#6.

51 CH-BAR\#E2300\#1000-716\#1202\#1\#206.

52 Alexandre Denis / Samuel Cruz-Lara / Nadia Bellalem: "General Purpose Textual Sentiment Analysis and Emotion Detection Tools«, in: ArXiv:1309.2853 [Cs] (2013), online at: http://arxiv.org/ abs/1309.2853 (1. 8. 2018).

53 Andrew L. Maas et al.: "Learning Word Vectors for Sentiment Analysis«, in: Proceedings of the 49th Annual Meeting of the Association for Computational Linguistics. Human Language Technologies, Portland, Oregon 2011, pp. 142-150, online at: http:// www.aclweb.org/anthology/P11-1015 (1. 8. 2018).

54 For a recent review, see Jaspreet Singh / Gurvinder Singh / Rajinder Singh: "Optimization of sentiment analysis using machine learning classifiers«, in: Human-Centric Computing and Information Sciences 7/1 (2017): p. 32, online at: https://doi.org/10.1186/s13673-0170116-3 (1. 8. 2018).

55 Vivek Narayanan / Ishan Arora / Arjun Bhatia: "Fast and Accurate Sentiment Classification Using an Enhanced Naive Bayes Model«, in: Lecture Notes in Computer Science 8206 (2013), pp. 194- 
201, online at: https://link.springer.com/content/pdf/10.1007\% 2F978-3-642-41278-3_24.pdf (1. 8. 2018).

56 One is Twitter dataset from Semeval-2016 task 4 and the other is Sentiment Treebank dataset constructed by Stanford University including two subtasks: binary classification and fine-grained classification of the sentence sentiment polarity.

57 Zu-Fan Zhang / Yan Zou / Chenquan Gan: "Textual sentiment analysis via three different attention convolutional neural networks and cross-modality consistent regression «, in: Neurocomputing 275 (2018), pp. 1407-1415.

58 Such an approach has been conducted, see A. Joshi / A. Balamurali / P. Bhattacharyya (2010). A fall-back strategy for sentiment analysis in hindi: a case study. Proceedings of the 8th ICON, for the construction of a Hindi sentiment lexicon.

59 Kenneth Benoit et al. contributors:: »quanteda: An R package for the Quantitative Analysis of Textual Data«. GitHub. Retrieved from https://github.com/quanteda/quanteda (Original work published 2012). This citation pertains to a software: a collective open source development initiated by first author; also the one of Tyler Rinker below.

60 Namely tidytext, see Julia Silge / David Robinson: Text Mining with R. O'Reilly, Beijing 2017, online at: http://tidytextmining.com/ index.html (1. 8. 2018); idem.: Tidytext. Text Mining and Analysis Using Tidy Data Principles in $\mathrm{R}$, in: The Journal of Open Source Software 1/3 (2016), p. 37, and sentimentr, see Tyler Rinker: "sentimentr: Dictionary based sentiment analysis that considers valence shifters«. GitHub. Retrieved from https://github.com/ trinker/sentimentr (Original work published 2015); Tyler Rinker: "A data package containing lexicons and dictionaries for text analysis« GitHub«. Retrieved from https://github.com/trinker/ lexicon (Original work published 2016). In tidytext, the NRCEmoLex can be found in the tidytext::sentiments data table, along with AFINN, see Finn Årup Nielsen: »A new ANEW: Evaluation of a word list for sentiment analysis in microblogs", in: Proceedings of the ESWC2011 Workshop on »Making Sense of Microposts«. Big things come in small packages, 2011, online at: http://arxiv.org/ abs/1103.2903 (1. 8. 2018); Bing, see Minqing Hu / Bing Liu: »Mining and Summarizing Customer Reviews", in: Proceedings of the Tenth ACM SIGKDD International Conference on Knowledge Discovery and Data Mining, New York 2004, pp. 168-177, online at: https:// doi.org/10.1145/1014052.1014073 (1. 8. 2018) and the polarity lexica. In lexicon, it is stored in lexicon::nrc_emotions (8 emotions) and in lexicon::hash_sentiment_nrc (polarities), see Tim Loughran / Bill McDonald: When is a Liability not a Liability? Textual Analysis, Dictionaries, and 10-Ks (SSRN Scholarly Paper No. ID 1331573), Rochester, NY 2010.

61 Amine Abdaoui et al.: »FEEL. A French Expanded Emotion Lexicon«, in: Language Resource and Evaluation 51/3 (2017), pp. 833-855, online at: https://doi.org/10.1007/s10579-016-9364-5 (1. 8. 2018).

62 Why the authors prefer Ekman's emotion set instead of Plutchik's is not clear from their paper.

63 Sagot: "The Lefff«.

64 Stopwords include for example logical conjunctions (et, ou, cepedant...), personal pronouns or locatives. We have also removed the weak verbs faire, être and avoir.

65 Helmut Schmid: »Probabilistic part-of-speech tagging using decision trees", in: Proceedings of International Conference on New Methods in Language Processing 12/4 (1994), pp. 44-49; idem: »Improvements in part-of-speech tagging with an application to German«, in: Proceedings of the ACL SIGDAT-Workshop, Dublin 1995.
66 Matthew Honnibal et al.: "SpaCy. Industrial-strength Natural Language Processing (NLP) with Python and Cython «, Explosion AI, 2018, online at: https://github.com/explosion/spaCy (1. 8. 2018) (Original work published 2014).

67 Milan Straka / Jan Hajic / JanaStraková: „UDPipe: Trainable Pipeline for Processing CoNLL-U Files Performing Tokenization, Morphological Analysis, POS Tagging and Parsing« in: Proceedings of the Tenth International Conference on Language Resources and Evaluation, Portorož 2016.

68 Loughran / McDonald: When is a Liability.

69 Salud María Jiménez-Zafra et al.: "Domain Adaptation of Polarity Lexicon combining Term Frequency and Bootstrapping", in: Proceedings of NAACL-HLT, pp. 137-146.

70 Janyce Wiebe / Rebecca Bruce / Thomas O'Hara: „Development and use of a gold standard data set for subjectivity classifications", in: Proceedings of the 37th Annual Meeting of the Association for Computational Linguistics (ACL-99), 1999, pp. 246-253; Stefano Baccianella / Andrea Esuli / Fabrizio Sebastiani: "SentiWordNet 3.0. An Enhanced Lexical Resource for Sentiment Analysis and Opinion Mining«, in: Proceedings of LREC, 2010.

71 CH-BAR\#E2300\#1000-716\#314\#5\#5

72 Here, we also include texts from wide time spans.

73 Christian W. Spang / Rolf-Harald Wippich. (ed.): Japanese-German Relations, 1895-1945. War, Diplomacy and Public Opinion, London 2006.

74 See Ourednik: L'habitant, pp. 156-195. This notion of syntheticity can be traced back, for instance, to Spinoza's conatus (Ethica 3, 6), in particular in its interpretation in terms of swill by Nietzsche, and further translation into the Freudian Ich at the interface of the Es and the exterior world. It also relates to Leibniz's notion of monad and its sociological interpretation by Gabriel Tarde, first indirectly, see Bruno Latour: Reassembling the Social, Oxford 2005, and then directly adopted by Bruno Latour in his actor-network theory, see Bruno Latour et al.: "'The whole is always smaller than its partsı, a digital test of Gabriel Tardes' monads", in: The British Journal of Sociology 63/4 (2012), pp. 590-615, online at: https://doi.org/10.1111/j.1468-4446.2012.01428.x (1. 8. 2018). The synthetic individual can also be conceived of as the self of an autopoietic system constructed by the system's observer, see Ourednik: L'habitant, p. 163; cf. Humberto Maturana / Francisco Varela: De Maquinas y Seres Vivos, Editorial Universitaria 1972. The synthetic subject of emotion should be conceived of as a logical place from which a sentiment about the world can be assessed and interpreted.

75 In effect, the Swiss foreign office has noted that the emotional world of ambassadors evolve and diverge with time spent in remote cultural settings. It sought to counter this by limiting the time spent by an envoy in a single country: to five, four and finally three years.

76 In allusion to James C. Scott's famous Book (James C. Scott: Seeing Like a State. How certain Schemes to Improve the Human Condition Have Failed, New Haven 1998).

77 Wilhelm Dilthey: Der Aufbau der geschichtlichen Welt in den Geisteswissenschaften, Frankfurt am Main 1910 [1970], at p. 85196.

78 Gilles Deleuze / Félix Guattari: Kafka, pour une littérature mineure, Paris 1975.

79 Keller: Botschafterporträts, p. 348.

80 Patrick Ziltener (ed.): Handbuch Schweiz - Japan. Diplomatie und Politik, Wirtschaft und Geschichte, Wissenschaft und Kultur. Texte, Dokumente und Bilder aus 400 Jahren gegenseitiger Beobachtung, Austausch und Kooperation, Zürich 2010. 
81 E2300\#1000/716\#1085*, 175 / [12], Tokio, Politische Berichte und Briefe, Militärberichte, Band 12, 1943-1945.

82 E2300\#1000/716\#1085*, 175 / [12], Tokio, Politische Berichte und Briefe, Militärberichte, Band 12, 1943-1945.

83 Chapter "Global results and interpretation«.

84 Gorgé has also published essays and poetry prior and after his diplomatic career. See also Pierre-Yves Donzé et al. (eds.): ») ournal d'un témoinc. Camille Gorgé, diplomate suisse dans le Japon en guerre (1940-1945)«, in: Dodis. Diplomatische Dokumente der Schweiz, 2018, online at: http://dodis.ch/dds/11280 (1. 8. 2018).

85 Scheer: »Are Emotions a Kind of Practice».

86 Eidgenössischer Staatskalender, 1946, Politisches Departement, Türkei (Ankara), 39, online at: https://www.amtsdruckschriften.bar. admin.ch/viewOrigDoc/40001842.pdf?id=40001842 (1. 8. 2018).

87 E2300\#1000/716\#1015*, 166 / [6], Stockholm, Politische Berichte und Briefe, Militärberichte, Band 6, 1928-1931.

88 Irène Lindgren / Renate Walder (eds.): Schweden, die Schweiz und der Zweite Weltkrieg, Bern 2001.

89 Karin Naumann: Utopien von Freiheit. die Schweiz im Spiegel schwedischer Literatur, Berlin 1994.

90 CH-BAR\#E2300\#1000-716\#1015\#2\#9, E2300\#1000/716\#1015*, $166 /$ [6], Stockholm, Politische Berichte und Briefe, Militärberichte, Bd. 6, 1928-1931.

91 Eric Flury-Dasen: "Schweden«, in: Historisches Lexikon der Schweiz, online at: http://www.hls-dhs-dss.ch/textes/d/D3371.php (1. 8. 2018).

92 Linus von Castelmur: Schweizerisch-Alliierte Finanzbeziehungen im Übergang vom Zweiten Weltkrieg zum kalten Krieg. Die deutschen Guthaben in der Schweiz zwischen Zwangsliquidierung und Freigabe (1945-1952), Zürich 1992; Marco Durrer: Die schweizerischamerikanischen Finanzbeziehungen im Zweiten Weltkrieg. Von der Blockierung der schweizerischen Guthaben in den USA über die "Safehaven«-Politik zum Washingtoner Abkommen (1941-1946), Bern 1984.

93 See, for instance, the information of the FDFA to the bilateral relations to these countries. For France in particular, online at: https://www.eda.admin.ch/eda/en/home/representations-andtravel-advice/france/switzerland-france.html (1. 8. 2018).

94 Keller: Botschafterporträts, p. 348. 


\section{Abstract}

Can emotions be observed throughout the years at the regional scale of continents and countries? Does variation in their intensity correlate with historical events and with the evolution of diplomatic and administrative practices? If so, who is the subject of emotion? We seek answers by a remote reading analysis of the reports of Swiss ambassadors in the first half of the 20th century. We examine the conditions under which super-individual subjects of emotion can be aggregated from large textual datasets, and propose a theoretical framework for their interpretation. In specific examples, we show how algorithmic sentiment analysis let us identify the exceptionally expressive language of the Swiss ambassador in Tokyo during World War 2, or the posture of the Swiss administration with regard to the social movements in Scandinavia. Our findings yield both methodological recommendations and theoretical bridges between various disciplines concerned with emotions and their expression in written documents.

\section{About the Authors}

André Ourednik is a scientific associate at the Historical Analysis Services of the Swiss Federal Archives, Berne, lecturer at the faculty of Social and Human Sciences of the EPFL and at the department of geography of the University of Neuchatel, and fiction writer. He holds a Ph.D. from the doctoral school Architecture and Sciences of the City of the EPFL.

Guido Koller is a scientific associate at the Historical Analysis Services of the Swiss federal archives, Berne. He holds a Ph.D. in History from the University of Basel and published widely on World War II, Refugee Policy and Digital History.

Peter Fleer is a scientific associate at the Historical Analysis Services of the Swiss federal archives, Berne. He holds a Ph.D. in History from the University of Bern and published on administrative and Latin American history.

Stefan Nellen leads the Historical Analysis Services of the Swiss Federal Archives, Berne. He holds a Ph.D. in History from the University of Basel and published widely on the history of public administration and governmentality. 